\title{
Connexin29 Is Uniquely Distributed within Myelinating Glial Cells of the Central and Peripheral Nervous Systems
}

\author{
Bruce M. Altevogt, ${ }^{2 *}$ Kleopas A. Kleopa, ${ }^{3 *}$ Friso R. Postma, ${ }^{1}$ Steven S. Scherer, ${ }^{3}$ and David L. Paul ${ }^{1}$ \\ ${ }^{1}$ Department of Neurobiology and 2Program in Neuroscience, Harvard Medical School, Boston, Massachusetts 02115, \\ and ${ }^{3}$ Department of Neurology, The University of Pennsylvania Medical Center, Philadelphia, Pennsylvania 19104-6077
}

\begin{abstract}
Although both Schwann cells and oligodendrocytes express connexin32 (Cx32), the loss of this connexin causes demyelination only in the PNS. To determine whether oligodendrocytes might express another connexin that can function in place of Cx32, we searched for novel CNS-specific connexins using reverse transcriptase-PCR and degenerate primers. We identified Cx29, whose transcript was restricted to brain, spinal cord, and sciatic nerve. Developmental expression of Cx29 mRNA in the CNS paralleled that of other myelin-related mRNAs, including Cx32. In the CNS, Cx29 antibodies labeled the internodal and juxtaparanodal regions of small myelin sheaths, whereas Cx32 staining was restricted to large myelinated fibers. In the PNS, Cx29 expression preceded that of Cx32 and declined to
\end{abstract}

Gap junctional intercellular communication (GJIC) is commonly observed in glial cells. Its importance is underscored by the fact that mutations in the gap junction protein connexin32 (Cx32) cause a demyelinating peripheral neuropathy, X-linked CharcotMarie-Tooth disease (CMTX) (Bergoffen et al., 1993). Myelinating Schwann cells express Cx32, and the expression of Cx32 mRNA parallels that of other myelin genes, such as $\mathrm{mpz}$ (Scherer et al., 1995). Freeze-fracture electron microscopy (EM) suggests that gap junctions are not found between adjacent myelinating Schwann cells but instead may comprise "reflexive" gap junctions that connect different regions of the same cell (Sandri et al., 1977; Tetzlaff, 1982). In accord with these results, Cx32 is restricted to paranodal membranes and Schmidt-Lanterman incisures, regions retaining cytoplasm that provide continuity between the perinuclear and periaxonal cytoplasm (Bergoffen et al., 1993; Scherer et al., 1995). Reflexive gap junctions at the paranodes and incisures would greatly shorten the distance for diffusion of nutrients or signals within myelinating Schwann cells. In support of the existence of reflexive junctions, junction-permeant molecules microinjected into the perinuclear cytoplasm diffuse rapidly into periaxonal regions, whereas junction-impermeant molecules do not (Balice-Gordon et al., 1998).

A loss of reflexive coupling caused by $c x 32$ mutations could underlie peripheral demyelination in CMTX. However, nerve

\footnotetext{
Received March 27, 2002; revised May 7, 2002; accepted May 10, 2002.

This work was supported by National Institutes of Health (NIH) Grant RO1 GM37751 (D.L.P.), NIH Grant F31 NS41730 (B.M.A.), a National Multiple Sclerosis Society Fellowship (K.A.K.), NIH Grant RO1 NS42878 (S.S.S.), and NIH Grant RO1 GM18974 (D.A. Goodenough). We thank Susan Shumas, Theodore Xu, and Marta Mastroianni for their expert technical assistance.

*B.M.A. and K.A.K. contributed equally to this work.

Correspondence should be addressed to David L. Paul, Department of Neurobiology, Harvard Medical School, 220 Longwood Avenue, Boston, MA 02115. E-mail: dpaul@hms.harvard.edu.

Copyright (C) 2002 Society for Neuroscience $\quad 0270-6474 / 02 / 226458-13 \$ 15.00 / 0$
}

lower levels than Cx32 in adulthood. In adult sciatic nerve, Cx29 was primarily localized to the innermost aspects of the myelin sheath, the paranode, the juxtaparanode, and the inner mesaxon. Cx29 displayed a striking coincidence with $\mathrm{Kv} 1.2 \mathrm{~K}^{+}$ channels, which are localized in the axonal membrane. Both Cx29 and Cx32 were found in the incisures. Cx29 expressed in N2A cells did not induce intercellular conductances but did participate in the formation of active channels when coexpressed with Cx32. Together, these data show that Cx29 and Cx32 are expressed by myelinating glial cells with distinct distributions.

Key words: Gap junction; connexin; myelin; oligodendrocyte; Schwann cell; Cx29

conduction velocities in $c x 32$-null mice are nearly normal, and compared with other animal models of inherited demyelinating neuropathy, demyelination begins rather late (Anzini et al., 1997; Scherer et al., 1998; Neuberg et al., 1999; Willecke et al., 1999). Thus, although human Schwann cells require Cx32 to maintain functionality, murine Schwann cells may be less dependent. One explanation for this difference could be the presence of additional connexins in murine incisures and paranodes. In support of this idea, the movement of junction-permeant dye from the perinuclear to the periaxonal cytoplasm is normal in cx32-null mice (Balice-Gordon et al., 1998). Redundancy or compensatory regulation of connexin expression could account for persistence of dye movement and the milder peripheral phenotype in mice lacking Cx32.

Multiple connexin expression could also explain why CMTX patients seldom have clinical CNS manifestations (Kleopa et al., 2002). In oligodendrocytes, Cx32 is localized on the outer aspects of myelin sheaths and oligodendrocyte cell bodies (Scherer et al., 1995; Li et al., 1997). Like Schwann cells, oligodendrocyte paranodal membranes enclose cytoplasm connecting the cell body to periaxonal regions and are found to contain gap junction-like particles by freeze-fracture EM (Sandri et al., 1977). However, Cx32 is not found in CNS paranodes (Scherer et al., 1995), with possible rare exceptions ( $\mathrm{Li}$ et al., 1997). Thus, the connexins forming paranodal gap junctions in oligodendrocytes remain to be identified. In addition, oligodendrocytes, unlike Schwann cells, have robust GJIC with other cells (Massa and Mugnaini, 1982; Li et al., 1997; Rash et al., 2001). Therefore, gap junctions in oligodendrocytes could have more than one function.

With these issues in mind, we searched for novel connexins in the CNS, using reverse transcriptase (RT)-PCR and degenerate primers. We identified $\mathrm{Cx} 29$, whose transcript was restricted to brain, spinal cord, and sciatic nerve. In the spinal cord, Cx29 was 
primarily found in myelin sheaths surrounding small fibers, whereas Cx32 staining was primarily found in myelin sheaths surrounding large myelinated fibers. Myelinating Schwann cells expressed both connexins, but their intracellular localization was different. Cx29 was primarily localized to the innermost aspects of the myelin sheath, the paranode, juxtaparanode, and the inner mesaxon and displayed a striking coincidence with axonal Kv1.2 $\mathrm{K}^{+}$channels. In contrast, $\mathrm{Cx} 32$ was primarily found in paranodes, whereas incisures contained both Cx29 and Cx32. Cx29 by itself did not induce GJIC in N2A cells; however, in combination with $\mathrm{Cx} 32$, it formed channels with novel properties.

\section{MATERIALS AND METHODS}

$P C R$ and genomic cloning. Adult mouse brain cDNA was synthesized from total RNA extracted using TRIzol (Invitrogen, Gaithersburg, MD) and reverse transcribed with Superscript II RNase H-reverse transcriptase (Invitrogen). Two degenerate oligonucleotides were synthesized corresponding to the first and second extracellular loop of seven connexins expressed in the CNS ( $\mathrm{mCx} 26, \mathrm{hCx} 32, \mathrm{pCx} 34.7, \mathrm{pCx} 35, \mathrm{mCx} 36, \mathrm{mCx} 43$, and $\mathrm{mCx} 45)$. The upstream primer $5^{\prime}-\mathrm{CA}(\mathrm{GA}) \mathrm{CC}(\mathrm{TGAC}) \mathrm{GG}(\mathrm{CT}) \mathrm{TG}-$ (TC)(AG)A(CGA)(AC)(AG)(TGC)G(TC)(CAT)TGC-3' was 13,824-fold degenerate. The downstream primer $5^{\prime}-(\mathrm{AG})(\mathrm{GT}) \mathrm{GAA}(\mathrm{GCA}) \mathrm{A}(\mathrm{CT})$ (GTCA)GT(CT)TT(CT)TC(CGAT)GT(GA)GG-3' was 3072-fold degenerate. RT-PCR (Advantage II; Clontech, Cambridge, UK) was performed using the following conditions: $95^{\circ} \mathrm{C}$ for $5 \mathrm{~min}, 94^{\circ} \mathrm{C}$ for $15 \mathrm{sec}, 55^{\circ} \mathrm{C}$ for 15 sec, and $72^{\circ} \mathrm{C}$ for $45 \mathrm{sec}\left(10\right.$ cycles); $94^{\circ} \mathrm{C}$ for $15 \mathrm{sec}, 43^{\circ} \mathrm{C}$ for $15 \mathrm{sec}$, and $72^{\circ} \mathrm{C}$ for $45 \mathrm{sec}(30$ cycles). RT-PCR products were separated on $1 \%$ agarose Tris-acetate-EDTA gel. Seven bands were individually purified (Qia-quick; Qiagen, Hilden, Germany) and subcloned into pCRII-TOPO (Invitrogen). Clones (672) were screened using PCR to eliminate colonies containing Cx32 or Cx43, leaving 448 clones that were screened for redundancy by restriction analysis with $A l u \mathrm{I}$ (New England Biolabs, Beverly, MA). The remaining 101 clones were sequenced, yielding four copies of a $750 \mathrm{bp}$ clone with significant homology to the connexin gene family.

To obtain the complete coding sequence of the putative connexin clone, a high-stringency screen was performed on a $129 \mathrm{SvEv}$ genomic library (Stratagene, La Jolla, CA). The original 750 bp amplicon was radiolabeled with ${ }^{32} \mathrm{P}$ by random priming (Roche Molecular Biochemicals, Hertforshire, UK). Hybridization and plaque isolation were performed as described previously (Haefliger et al., 1992). Isolated phage DNA was digested with NotI (New England Biolabs), yielding a single 16 $\mathrm{kb}$ fragment that was subcloned into pDTA (gift from Frank Gertler, Massachusetts Institute of Technology, Cambridge, MA). The coding sequence obtained (AF503616) has 100\% homology with a connexin recently submitted to GenBank (AJ297318) (Sohl et al., 2001). In addition, a putative human ortholog (hCx31.3; AF503615) was identified in a blast search of the National Institutes of Health high throughput genomic sequences (HTGS) database (AC004977, AC011904, and AC004522).

Tissue collection for Northern blot analysis and in situ hybridization. For Northern blot analysis, the sciatic nerves of anesthetized $(50 \mathrm{mg} / \mathrm{kg}$ pentobarbital, i.p.), adult (10-13 weeks old) Sprague Dawley rats were exposed at the sciatic notch. Permanent axotomy was accomplished by doubly ligating nerves, transecting between the ligatures with iridectomy scissors, and suturing the two nerve stumps $\geq 1 \mathrm{~cm}$ apart. This technique prevents axonal regeneration to the distal nerve stump for $\geq 2$ months. Nerve crush was produced by tightly compressing the sciatic nerve at the sciatic notch with flattened forceps twice, each time for $10 \mathrm{sec}$; this technique causes all of the axons to degenerate but allows axonal regeneration. At various times after nerve injury, the animals were killed by $\mathrm{CO}_{2}$ inhalation, the distal nerve stumps were removed, and the most proximal $2-3 \mathrm{~mm}$ were trimmed off. For transected nerves, the entire distal nerve stump was taken from just below the lesion to the ankle $(\sim 4$ $\mathrm{cm}$ ). For crushed nerves, the distal nerve stump was divided into two equal segments, termed D1 (nearest the lesion) and D2, each $\sim 2 \mathrm{~cm}$ long. The nerves were immediately frozen in liquid nitrogen and stored at $-80^{\circ} \mathrm{C}$. Unlesioned sciatic nerves and various brain regions were obtained from animals of different ages, from postnatal day 1 (P1) to P90. All animal protocols were approved by the Institutional Animal Care and Use Committee (IACUC) of The University of Pennsylvania.

Total RNA was isolated and RNA blots were performed as described previously (Scherer et al., 1995) using $10 \mu \mathrm{g}$ of total RNA per sample. The original PCR amplicon, glyceraldehyde 3-phosphate dehydrogenase (GAPDH; produced using PCR amplification of genomic DNA), rat
Cx32 (Paul, 1986), rat $\mathrm{P}_{0}$ (Lemke and Axel, 1985), proteolipid protein (PLP) (Milner et al., 1985), and the low-affinity nerve growth factor receptor/p75 (Radeke et al., 1987) were used as probes.

For in situ hybridization (ISH), adult mice (age 3-6 months) were killed following IACUC guidelines. The brain and spinal cord were dissected and fixed for $1 \mathrm{hr}$ at room temperature in $4 \%$ paraformaldehyde, rinsed with PBS, and cryoprotected overnight in $30 \%$ sucrose/PBS. Tissue was embedded in optimal cutting temperature (OCT; Tissue-Tek; Miles, Elkhart, IN), frozen, and sectioned at $12 \mu \mathrm{m}$. In situ hybridization was performed using digoxigenin-labeled riboprobes. To assure specificity, three different probes for Cx29 were used. The first was a full-length coding region probe with $53 \mathrm{bp} 5^{\prime}$ to the start and $97 \mathrm{bp} 3^{\prime}$ to the stop codon. To produce separate nonoverlapping probes, the original probe was digesting with HindIII, and the resulting fragments were subcloned into pBluescript SK (Stratagene). All three probes produced the same pattern of labeling. A full-length probe for rat PLP (Milner et al., 1985) was also used. In situ hybridization was performed as described by Rodriguez and Dymecki (2000). After detecting RNA, some slides were counterstained with antibodies to various markers. Slides were rinsed for 5 min with PBS and blocked for $30 \mathrm{~min}$ at room temperature in $5 \%$ fish gelatin and $0.1 \%$ Triton in PBS. Anti-neuron-specific nuclear protein (NeuN) (Chemicon, Temecula, CA) and anti-GFAP (Sigma, St. Louis, MO) antibodies were diluted in blocking solution 1:100 and incubated at $4^{\circ} \mathrm{C}$ overnight. Slides were then washed three times with PBS for $3 \mathrm{~min}$ each. Primary antibody binding was detected using $\mathrm{ABC}$ Elite $\mathrm{DAB}$ (Vector Laboratories, Burlingame, CA) according to the manufacturer's directions and photographed using a Nikon E800 (Tokyo, Japan) equipped with a SPOT II digital camera.

Preparation of anti-Cx29 antibodies. A bacterial fusion protein containing glutathione $S$-transferase (GST) plus the C-terminal portion of Cx29 (amino acids 220-258) was produced using the vector pGEX-4T-3 as described previously (Jiang et al., 1994). The Cx29 portion was cleaved from GST using thrombin, purified, and used to immunize rabbits (Pocono Rabbit Farm, Canadensis, PA). The resultant antisera were affinity purified using column-bound fusion protein as described previously (Gabriels and Paul, 1998). Anti-peptide antibodies against two different $\mathrm{C}$-terminal domains of Cx29 were also produced. Rabbits were immunized with peptides corresponding to residues $234-245$ or $240-258$ (BioSource International, Hopkinton, MA). Antisera were then affinity purified using column-bound peptide.

Western blots. A positive control for Western blotting was obtained by transfection of COS cells. Construction of the expression vector and transfection are as described below in the section discussing Cx29 channel physiology, except that COS cells were used. After a $2 \mathrm{~d}$ incubation, transfected cells were trypsinized and washed three times with PBS Cells from one confluent $36 \mathrm{~mm}$ dish were resuspended in $200 \mu \mathrm{l}$ of 50 mM Tris, $\mathrm{pH} 7.6,1 \%$ SDS, $0.017 \mathrm{mg} / \mathrm{ml}$ phenylmethylsulfonyl fluoride, $0.05 \mu \mathrm{l} / \mathrm{mg}$ Sigma Protease Inhibitor cocktail P8340, and $18.5 \mu \mathrm{l} / \mathrm{ml}$ di-isopropylfluorophosphate; sonicated; and combined with $3 \times$ SDSPAGE loading buffer (150 mM Tris, pH 7.6, 6\% SDS, 30\% glycerol, 0.3\% bromophenol blue, and $300 \mathrm{~mm}$ DTT).

After separation on $4-20 \%$ acrylamide gels, proteins were transferred at $100 \mathrm{~V}$ for $70 \mathrm{~min}$ in $1 \times$ transfer buffer $(0.2 \%$ methanol, $2.5 \mathrm{~mm}$ Tris, and $19.2 \mathrm{M}$ glycine) onto Protran nitrocellulose pore $0.45 \mu \mathrm{m}$ (Schleicher and Schuell, Keene, $\mathrm{NH}$ ), blocked for $1 \mathrm{hr}$ at room temperature [5\% dry milk, $1 \times$ Tris-buffered saline with $1 \%$ Tween 20 (TBST)], and blotted overnight at $4^{\circ} \mathrm{C}$ in affinity purified fusion protein anti-Cx29 (anti-Cx29 $1: 8,5 \%$ dry milk, $1 \times$ TBST). Blots were washed three times for 3 min in $1 \times$ TBST, incubated in 1:3000 anti-rabbit HRP-conjugated secondary antibody (170-6515; Bio-Rad, Richmond, CA) (1\% dry milk, $1 \times$ TBST) for $45 \mathrm{~min}$ at room temperature, and washed with $1 \times$ TBST three times for $3 \mathrm{~min}$; antibody binding was detected using ESL (Amersham Biosciences, Arlington Heights, IL) according to the manufacturer's recommendations.

Immunohistochemistry. Unfixed mouse or rat sciatic nerves and spinal cords were embedded in OCT and immediately frozen in a dry ice acetone bath. These tissues were also embedded in OCT after brief fixation (30-60 $\mathrm{min}$ ) in either freshly prepared $4 \%$ paraformaldehyde in $0.1 \mathrm{M}$ phosphate buffer (PB), $\mathrm{pH} 7.4$, or Zamboni's fixative (4\% paraformaldehyde in $0.1 \mathrm{M}$ PB plus $15 \% \mathrm{v} / \mathrm{v}$ saturated picric acid) (Zamboni and de Martino, 1967). Fixed tissues were infiltrated in $20 \%$ sucrose PB overnight before embedding. Cryostat sections $(5 \mu \mathrm{m})$ were thawedmounted on SuperFrost Plus glass slides (Fisher Scientific, Houston, TX) and stored at $-20^{\circ} \mathrm{C}$. Teased nerve fibers were prepared from adult mouse and rat sciatic nerves, both fixed and unfixed, dried on SuperFrost 
Plus glass slides overnight at room temperature, and stored at $-20^{\circ} \mathrm{C}$. Sections and teased fibers were postfixed and permeabilized by immersion in $-20^{\circ} \mathrm{C}$ acetone for $10 \mathrm{~min}$, blocked at room temperature for $\geq 1$ $\mathrm{hr}$ in 5\% fish skin gelatin containing $0.5 \%$ Triton X-100 in PBS, and incubated $16-48 \mathrm{hr}$ at $4^{\circ} \mathrm{C}$ with various combinations of primary antibodies: Anti-Cx29 (fusion protein, 1:300), mouse anti-Cx32 (Li et al., 1997; 7C6.C7, 1:2), mouse anti-rat myelin-associated glycoprotein (MAG) (clone 513; Boehringer Mannheim, Indianapolis, IN; 1:100), mouse anti-Caspr (Poliak et al., 1999; 1:50), and mouse anti-Kv1.2 (Alomone Laboratories, Jerusalem, Israel; 1:50). After incubating with the primary antibodies, the slides were washed and incubated with the appropriate fluorescein- and rhodamine-conjugated donkey crossaffinity-purified secondary antibodies (diluted 1:100; Jackson ImmunoResearch, West Grove, PA). Slides were mounted with Vectashield (Vector Laboratories), examined by epifluorescence with tetramethylrhodamine isothiocyanate and FITC optics on a Leica (Deerfield, IL) DMR light microscope, and photographed with a cooled Hamamatsu (Bridgewater, NJ) camera or with a Leica TCS laser-scanning confocal microscope, followed by image manipulation with Adobe PhotoShop (Adobe Systems, San Jose, CA).

Immuno-electron microscopy. In preliminary experiments, segments of adult rat sciatic nerves $(\sim 1 \mathrm{~cm}$ long) were fixed in either $4 \%$ paraformaldehyde and $0.1 \%$ glutaraldehyde (Mi et al., 1995), 3.75\% acrolein and $2 \%$ paraformaldehyde (Einheber et al., 1997), or $0.5 \%$ glutaraldehyde, all in $0.1 \mathrm{M} \mathrm{PB}, \mathrm{pH} 7.4$, for $1 \mathrm{hr}$ on ice. Teased fibers were prepared, placed in microfuge tubes, incubated in blocking solution (5\% fish skin gelatin, $0.5 \%$ Triton $\mathrm{X}-100$, in PBS) for $\geq 1 \mathrm{hr}$, and then incubated overnight at $4^{\circ} \mathrm{C}$ in a rabbit antisera against $\mathrm{Cx} 29$, diluted 1:500 in blocking solution. The teased fibers were rinsed in PBS, visualized with a Vector Elite ABC kit (Vector Laboratories) according to the manufacturer's instructions, using $0.5 \mathrm{mg} / \mathrm{ml} \mathrm{DAB}$ as a substrate, rinsed in PBS at room temperature, and mounted in glass slides in PBS. The preservation of myelin sheaths was poor with $4 \%$ paraformaldehyde and $0.1 \%$ glutaraldehyde, good with $0.5 \%$ glutaraldehyde, and excellent with $3.75 \%$ acrolein $/ 2 \%$ paraformaldehyde (data not shown); unfortunately, the amount of immunostaining was in the reverse order.

Based on these pilot experiments, we repeated the experiment with $0.5 \%$ glutaraldehyde fixation. After immunostaining, the teased fibers were fixed overnight in $3 \%$ glutaraldehyde in $0.1 \mathrm{M} \mathrm{PB}$, rinsed, osmicated in $1 \% \mathrm{OsO}_{4}$ (in $0.1 \mathrm{M} \mathrm{PB}$ ) for $1 \mathrm{hr}$ at room temperature, dehydrated in graded ethanols, infiltrated with Durcopan ACM resin, and placed between glass slides that had been treated with Liquid Release Agent (EMS, Ft. Washington, PA). After polymerization in a $60^{\circ} \mathrm{C}$ oven overnight, selected areas were trimmed and mounted on a Durcopan stub with cyanoacrylate adhesive. Semithin sections $(0.5 \mu \mathrm{m}$ thick $)$ were mounted on glass slides and photographed without counterstaining. Thin sections (silver interference color) were mounted on one hole, formvarcoated grids (EMS) and photographed in a Zeiss (Thornwood, NY) EM10 electron microscope without counterstaining. Light microscopic images of the teased fibers and semithin sections were generated with a cooled Hamamatsu camera. Electron micrographs were printed and scanned; these images were imported into Adobe PhotoShop and assembled.

Cx29 channel physiology. To produce a construct for expression of Cx29 in Xenopus oocytes and N2A cells, the $16 \mathrm{~kb}$ genomic clone was digested with DraI and BsgRI, and the fragment was subcloned into the StuI site of pCS2+. In addition, rat Cx32 cDNA (Paul, 1986) was subcloned into the EcoRI site of pCS2+. For oocyte studies, constructs were linearized with NotI, and RNA was produced using an SP6 Message Machine kit (Ambion, Austin, TX) according to the manufacturer's instructions. Oocytes were processed, injected, paired, and voltage clamped as described previously (Swenson et al., 1989)

Studies were also performed using dual whole-cell patch clamp in transiently transfected N2A cells. N2A neuroblastoma cells were grown in DMEM supplemented with $10 \%$ fetal calf serum. On reaching $80 \%$ cell density, cells were washed with DMEM/F-12 and transfected using lipofectamine (Invitrogen) according to the manufacturer's directions. Cells were transfected with either $1 \mu \mathrm{g}$ of $\mathrm{Cx} 29,0.2 \mu \mathrm{g}$ of $\mathrm{Cx} 32$, or both. Connexins were cotransfected with equivalent amounts of vectors expressing either enhanced green fluorescent protein (eGFP) or enhanced yellow fluorescent protein (eYFP) (Clontech) so that transfected cells could be identified for patch clamping. After transfection $(12 \mathrm{hr})$, cells were trypsinized, mixed in a 1:1 ratio, and reseeded in low density. Recordings of green/yellow fluorescent cell pairs were routinely initiated after $3 \mathrm{hr}$.



Figure 1. Cx29 is among the most divergent connexins. $A$, Alignment of Cx29 and hCx31.3 reveals $61 \%$ amino acid identity. Nonidentical residues are boxed. $B$, Dendrogram illustrating phylogenetic relationships based on CLUSTAL algorithm. These data suggest that $\mathrm{Cx} 29$ and $\mathrm{hCx} 31.3$ are orthologs and are among the most divergent members of the connexin family.

Double patch-clamp recordings were performed as described by Srinivas et al. (1999). Briefly, glass capillaries were pulled to a resistance of $\sim 5 \mathrm{M} \Omega$ (Sutter Instruments, Novato, CA) and filled with (in mM): 140 $\mathrm{CsCl}, 10 \mathrm{HEPES}, 1 \mathrm{MgCl}_{2}$, 5 EGTA, and $0.5 \mathrm{CaCl}, \mathrm{pH}$ 7.2. The extracellular solution contained (in mM): $140 \mathrm{NaCl}, 10 \mathrm{HEPES}, 2 \mathrm{CaCl}_{2}$, $1 \mathrm{MgCl}_{2}, 5 \mathrm{CsCl}$, and $10 \mathrm{D}$-glucose, $\mathrm{pH}$ 7.4. Patch amplifiers (EPC-7; Heka Electronik, Lambrecht/Pfalz, Germany, and Axoclamp 200B; Axon Instruments, Union City, CA) were interfaced to a personal computer-running pClamp 8 via the digidata1200 (Axon Instruments). After obtaining $\mathrm{G} \Omega$ seals, cell pairs were voltage clamped at $0 \mathrm{mV}$. Junctional conductance was determined by imposing $10 \mathrm{mV}$ transjunctional potentials. Pairs with junctional conductances exceeding $6 \mathrm{nS}$ were discarded. At the start of each sweep, a $10 \mathrm{mV}$ pulse was applied to normalize variance in resistance within one experiment. Offline data analysis was performed using Clampfit (Axon Instruments) and Excel (Microsoft, Seattle, WA). Curve fitting was performed using Origin 6.1 (Originlab, Northampton, MA).

\section{RESULTS}

\section{Cloning of Cx29}

PCR amplification of brain cDNA with degenerate primers for the two extracellular loops yielded seven distinct bands ranging in size from 200 to $750 \mathrm{bp}$ (data not shown). Each band was separately gel purified and subcloned. Colonies (96) of each were screened to eliminate known connexins. The remaining 101 subclones were sequenced, yielding four identical copies of a $750 \mathrm{bp}$ insert with significant homology to other connexins. To obtain the complete coding region, the $750 \mathrm{bp}$ insert was used to screen a 129SvEv genomic DNA library (Stratagene). Sequence analysis of the genomic clone revealed an open reading frame of $777 \mathrm{bp}$ (Fig. $1 A$ ), predicting a protein exhibiting features common to connexins, including four transmembrane domains and two extracellular 
domains with the characteristic three cysteine motif (White and Paul, 1999). Blast searches of murine expressed sequence tag (EST) databases confirmed the start codon, but available EST sequences terminated before the putative stop codon. To confirm the start and stop codons predicted in the genomic sequence, we performed RT-PCR using primers flanking those sites, which yielded the expected product (data not shown). Because the predicted molecular mass was $28.98 \mathrm{kDa}$, we designated this protein murine Cx29 (Altevogt et al., 2000) (AF503616). Recently, Sohl et al. (2001) retrieved the same sequence from an analysis of the Heidelberg Unix Sequence Analysis Resources/ European Molecular Biology Laboratory/Heidelberg database.

TblastN searches of the GenBank HTGS database using the mouse Cx29 sequence identified three human genomic segments. The connexin-related ORFs predicted by two of these (AC004977 and AC011904) were identical, whereas the other (AC004522) exhibited multiple stops and was likely a nonfunctional gene. The molecular mass of the connexin predicted by the first two was $30.31 \mathrm{kDa}$. This putative connexin was also described by Sohl et al. (2001), who tentatively designated it human Cx30.2 (hCx30.2). However, our Blast searches revealed a human EST predicting a different ultimate C-terminal domain (BI860607) yielding a protein with a predicted molecular mass of $31.298 \mathrm{kDa}$. This C-terminal sequence was validated by PCR of human brain cDNA (Clontech) as described above for Cx29 (data not shown), whereas no evidence of transcripts corresponding to the shorter form (hCx30.2) was obtained. The transcribed C-terminal coding sequence was found $5.2 \mathrm{~kb}$ downstream of the original ORF in human genomic DNA. On this basis, we conclude that the human gene contains an intron interrupting the coding region, which is not present in the murine gene. We have designated the human gene $C x 31.3$ (hCx31.3), and its sequence has been submitted to GenBank (AF503615).

Alignment of the $\mathrm{Cx} 29$ and $\mathrm{hCx} 31.3$ open reading frames revealed $61 \%$ identity. This high level of relatedness suggests that Cx29 and hCx31.1 are orthologs (Fig. 1A). As indicated by CLUSTAL analysis (Fig. $1 B$ ), Cx29 was more closely related to hCx31.3 than to any other murine connexin. The CLUSTAL algorithm also demonstrated that $\mathrm{Cx} 29$ and hCx31.3 were among the most divergent members of the connexin family. Although computer-aided analyses of connexin sequences suggest the grouping of connexins into subclasses (Sohl et al., 2001), consistent structural rules by which to define these subclasses have not emerged. Because the significance of these subclasses is unclear, we have not assigned $\mathrm{Cx} 29$ or hCx31.3 to a subclass, defined previously or new.

\section{Cx29 expression is restricted to the CNS and PNS and coordinately expressed with myelin genes}

To determine which tissues express Cx29, Northern blot analysis was performed on total RNA extracted from adult mouse organs. Cx29 mRNA was detected in the brain, as expected, because it was cloned from brain cDNA and spinal cord (Fig. 2A). Cx29 mRNA was also found in sciatic nerve, at higher levels relative to brain or spinal cord (compare Cx29 and GAPDH signals). Cx29 mRNA was below the level of detection in the other tissues examined. Together, these data suggest that Cx29 may be a product of myelinating glial cells.

To explore the relationship of $\mathrm{Cx} 29$ to CNS myelination, we compared its developmental profile with that of PLP, a major component of CNS myelin. In mouse cerebellum and cerebrum (Fig. 2B,C), temporal regulation of Cx29 mRNA expression was similar to that of PLP (Fig. 2B), although in the cerebellum (but not the cerebrum), Cx29 mRNA was detected earlier than PLP mRNA. The precocious appearance of Cx29 did not exclude the possibility that it was expressed only by oligodendrocytes, because other myelin-related mRNAs are expressed before PLP (Scherer et al., 1994). To further explore the possibility that oligodendrocytes express Cx29, we examined Cx29 mRNA levels in myelindeficient (MD) rats, in which oligodendrocytes die before they produce much myelin (Duncan et al., 1987). In contrast to littermate controls (Fig. 2D), neither Cx29 nor Cx32 were detected in $\mathrm{MD}$ rats (Fig. $2 E$ ). This was consistent with the reductions in levels of myelin-related mRNAs observed in MD rats (Scherer et al., 1995). Together, these data support the idea that oligodendrocytes express Cx29 as part of a program of myelin gene expression.

Because neuronal mRNAs are largely excluded from axons, the presence of Cx29 mRNA in sciatic nerve was most consistent with glial expression. We explored this idea by examining Cx29 mRNA expression in developing rat sciatic nerves. Surprisingly, Cx29 mRNA appeared earlier, and declined to lower levels in adulthood, than either $\mathrm{Cx} 32$ or $\mathrm{P}_{0}$ mRNAs (Fig. $2 F$ ). We also examined Cx29 mRNA expression after treatments affecting myelination in adult sciatic nerve. For this study, we performed whole-nerve transection or crush, which cause degeneration of axons distal to the injury and a dramatic reduction of myelinrelated gene expression in the Schwann cells that myelinated those axons previously (Mirsky and Jessen, 1990; Scherer and Salzer, 2001). After transection, regenerating axons do not reach the distal nerve stump, and thus, reinitiation of myelin-related gene expression does not occur. As shown in Figure $2 G, \mathrm{P}_{0}$ and Cx32 mRNA levels declined precipitously, whereas Cx29 mRNA remained at its characteristically low adult level. In crushed nerve, regenerating axons eventually invade the distal stump and myelin-related gene expression resumes. As expected, $\mathrm{P}_{0}$ and Cx32 mRNA levels declined after crush and then recovered first in the segment closest to the crush (D1) and later in the more distal segment (D2). These data suggest that $c \times 29$ is a myelin-related gene whose expression is regulated by axon-Schwann cell interactions.

\section{Cx29 is not expressed by astrocytes or neurons in the CNS}

To determine the cellular source of Cx29 mRNA in the CNS, ISH was performed on sections of adult mouse brain and spinal cord. Cells expressing Cx29 were located in both white and gray matter of spinal cord (Fig. $3 A$ ) and brain (data not shown) and typically exhibited small somata. Three different antisense probes produced similar patterns of labeling (data not shown). In addition, a full-length sense probe exhibited a low background (Fig. 3B). PLP/DM20 was also expressed by small cells in both white and gray matter, but PLP/DM20-positive cells were more numerous, especially in white matter (Fig. 3C). We observed no consistent difference in labeling patterns at different spinal levels for either PLP/DM20 or Cx29.

These data suggested that a subset of spinal cord oligodendrocytes expressed Cx29 but left open the possibility that other cell types also expressed Cx29. To investigate this possibility, ISH sections were labeled with antibodies to well characterized neuronal (NeuN) and astrocytic (GFAP) markers, which were visualized using peroxidase-conjugated secondary antibodies. Double staining for $\mathrm{Cx} 29$ by ISH (blue) and for the neuronal antigen (brown) is shown in Figure $4 A, B$. As expected, only cells in the gray matter were labeled for NeuN, which was particularly abundant in neuronal nuclei and to a lesser degree in their cytoplasm 


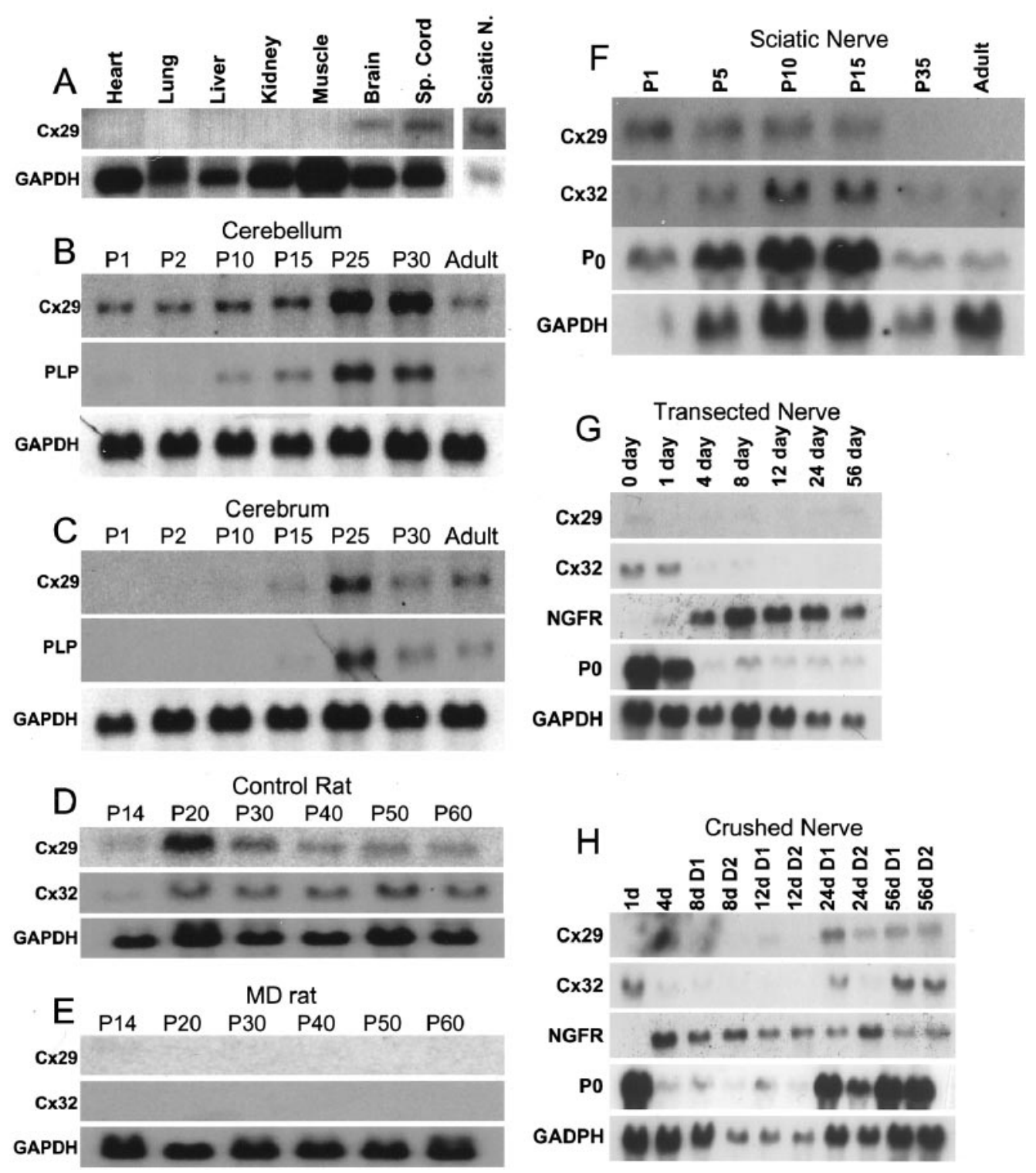

Figure 2. Cx29 is a nervous system-specific connexin and is expressed coordinately with other myelin-related genes. Northern blots of total RNA were hybridized with the indicated cDNA probes. $A$, Cx29 transcript is detected only in brain, spinal cord, and sciatic nerve of adult mice. $B, C$, Developmental pattern of Cx29 mRNA expression in mouse cerebellum $(B)$ and cerebrum $(C)$ generally parallels that of PLP (only the largest PLP transcript is shown). However, Cx29 is expressed earlier in the cerebellum. D, E, Male MD rats have undetectable levels of Cx29 and Cx32 mRNA compared with their age-matched unaffected male littermates. $F, \mathrm{Cx} 29$ is expressed before Cx32 mRNA in developing rat sciatic nerves and is barely detectable in adult nerves. $G, H$, The level of Cx29 mRNA increases in the distal stumps of crushed/regenerating adult rat sciatic nerves, paralleling those of $\mathrm{P}_{0}$ and Cx32, but in transected/permanently denervated distal stumps, Cx29, $\mathrm{P}_{0}$, and Cx32 mRNAs do not increase. NGFR, Nerve growth factor receptor.

(Mullen et al., 1992). The overall distributions of Cx29 and NeuN were clearly distinct, and overlap between Cx29 and NeuN was never detected at a cellular level (Fig. 4B). Similarly, every GFAP-positive astrocyte was Cx29 negative (Fig. 4C). Together, these data indicate that $\mathrm{Cx} 29$ was not expressed by neurons or GFAP-positive astrocytes in the spinal cord and was therefore likely expressed by a subset of oligodendrocytes in both white and gray matter. Similar results were obtained in studies of the brain (data not shown).

\section{Production and characterization of antibodies against Cx29}

Three different specific antibodies against Cx29 were generated. Two were anti-peptide antibodies directed against residues 234245 or $240-258$. Both peptide sequences are located within the cytoplasmic C-terminal domain of Cx29, and neither share significant homology with other connexins or any sequence currently deposited in mouse genomic and EST databases. The third antibody was produced against a GST fusion protein containing residues 220-258, which constituted the majority of the C-terminal domain and overlaps both peptides.

Western blotting was used to characterize the fusion-protein antibody (Fig. 5). Lane 1 of Figure 5 contains a positive control consisting of $10 \mathrm{ng}$ of GST fusion protein where a single immunoreactive band was observed. Although the predicted molecular mass of the fusion protein was $32 \mathrm{kDa}$, it displayed anomalous migration corresponding to $\sim 36 \mathrm{kDa}$. The labeling pattern in transiently transfected tissue culture cells was more complex. When transfected with Cx29 alone (data not shown) or with a 

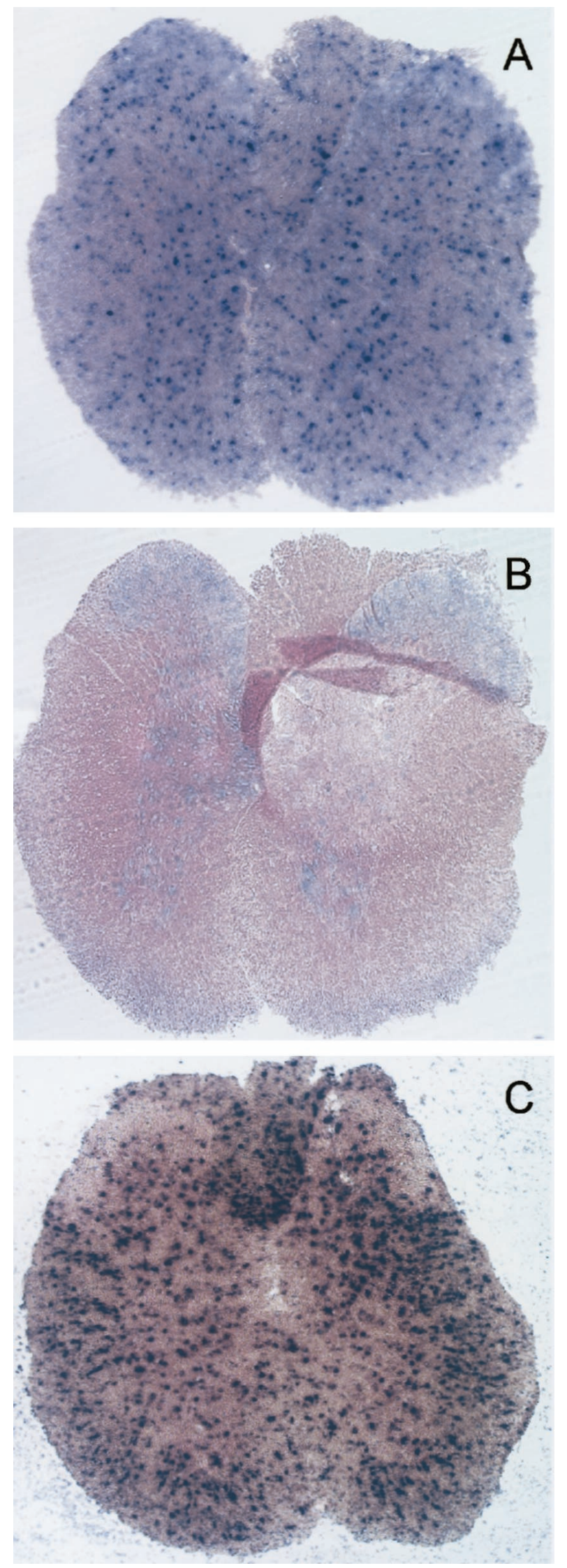

Figure 3. Cx29 is expressed by small cells in both white and gray matter of spinal cord. In situ hybridization in transverse sections of adult mouse spinal cord. $A$, An antisense Cx29 RNA probe corresponding to the combination of rat $\mathrm{Cx} 32$ (rCx32) and $\mathrm{Cx} 29$ (Fig. 5, lane 3), COS cells exhibited three immunoreactive bands. Strong bands were observed at 60 and $29 \mathrm{kDa}$, whereas a weak band was observed at $\sim 85 \mathrm{kDa}$. Preabsorption of the antibody with fusion protein eliminated the staining of these bands (data not shown). Cells transfected with rCx32 alone (Fig. 5, lane 2) or empty vector (data not shown) did not display immunoreactive bands.

Cx32 displays anomalous behavior in SDS-PAGE ascribed to stable association into dimers, trimers, and higher-order aggregates (Hertzberg, 1984; Paul, 1986). Thus, the presence of 60 and $85 \mathrm{kDa}$ bands may reflect a similar behavior for $\mathrm{Cx} 29$. However, Cx32 aggregation was increased by heating and increases in protein concentration (Hertzberg, 1984), whereas Cx29 aggregation was not affected by these parameters (data not shown). Thus, although Cx29 aggregation could be an artifact of sample preparation, it remains possible that it reflects a stable complex with other proteins or a biologically significant post-translational modification. Regardless, all three immunoreactive bands are clearly related to $\mathrm{Cx} 29$.

The labeling patterns in mouse tissues containing myelinated nerve resembled, but were not identical to, those of $\mathrm{Cx} 29$ transfected cells. Brain (Fig. 5, lane 4) and spinal cord (Fig. 5, lane 5) exhibited immunoreactive bands corresponding to those observed in COS cells plus additional bands. The complex profiles of brain and spinal cord could be explained in part by proteolytic processing of $\mathrm{Cx} 29$ and its aggregates. For example, spinal cord displayed a doublet at $29 \mathrm{kDa}$ that we also observed in some preparations of brain (data not shown). In addition, inclusion of protease inhibitors during the sample preparation reduced, although never eliminated, the additional immunoreactive bands (data not shown). In sciatic nerve (Fig. 5, lane 6), the $60 \mathrm{kDa}$ band was much more abundant than the others, which were only observed when high levels of sample were loaded (data not shown). Together, these data suggest that although Cx29 displayed anomalous behavior in SDS-PAGE, the fusion-protein antibody is specific for Cx29.

\section{Cx29 and Cx32 are expressed in different subsets of oligodendrocytes}

Double labeling was performed using rabbit anti-Cx29 antibodies together with mouse monoclonal antibodies to $\mathrm{Cx} 32$, Caspr, MAG, or Kv1.2. The monoclonal antibody against Cx32 does not stain any cellular element in cx32-null mice (Scherer et al., 1998), but in rat spinal cords, it labels oligodendrocyte somata, their processes, and the outer membrane of CNS myelin sheaths (Scherer et al., 1995). A similar pattern of staining for Cx32 was observed in horizontal sections of mouse spinal cord (Fig. 6A). The white matter contained abundant Cx32-positive somata, often in chains characteristic of intrafascicular oligodendrocytes. Cx32 labeling extended into fiber tracts, where it was not always possible to discriminate which structures were labeled. In contrast, Cx29 was clearly evident along the internodal region of smaller diameter fibers (Fig. 6A). The juxtaparanodal regions of these fibers were even more intensely labeled, as documented by double labeling for Caspr, which stained the paranodal axolemma (Fig. 6B), or Kv1.2 (data not shown), which stained juxtaparan-

coding region stains small cells throughout the cord. $B$, A sense $\mathrm{Cx} 29$ probe exhibits relatively low background. $C$, The pattern of hybridization with PLP/DM20 probe is similar to Cx29, but a larger number of cells are stained, especially in the white matter. 

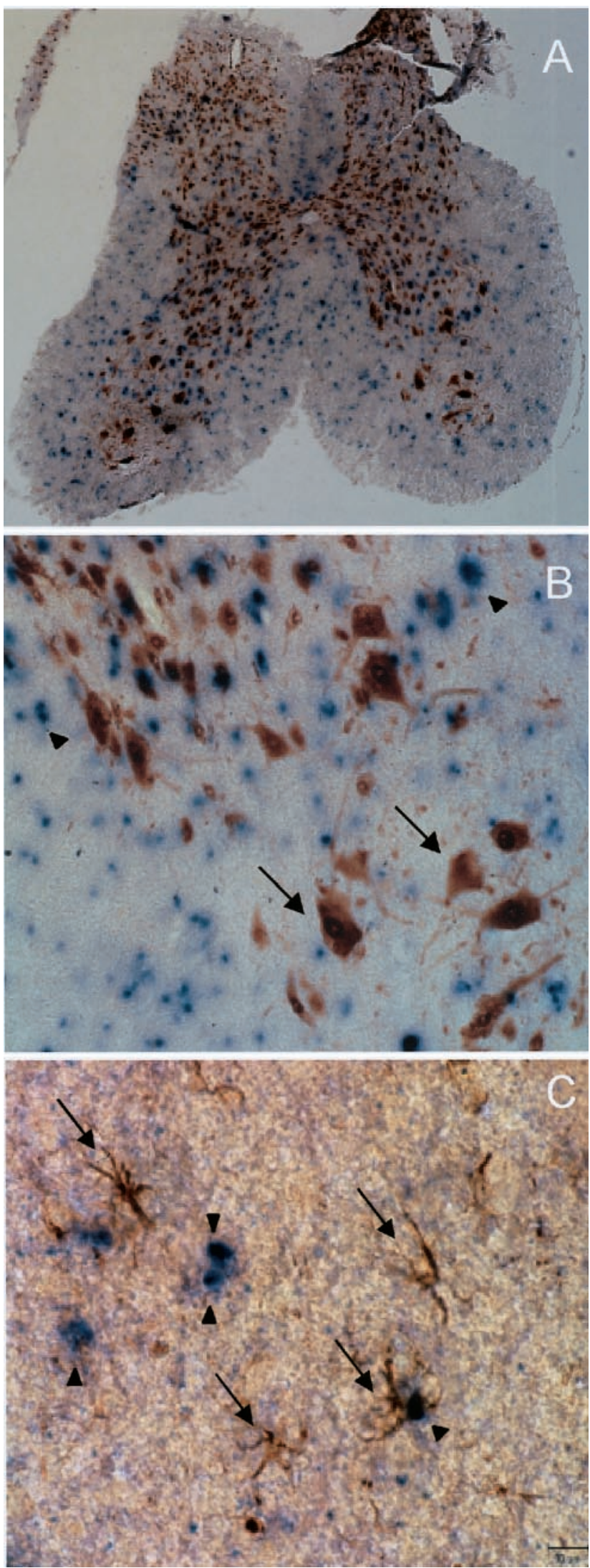

Figure 4. Cx29 is not expressed by neurons or astrocytes in spinal cord. In situ hybridization for $\mathrm{Cx} 29$ in transverse sections of spinal cord combined with immunocytochemistry for cell-specific markers is shown. $A, B$, Cells immunolabeled for NeuN do not correspond to cells labeled by in

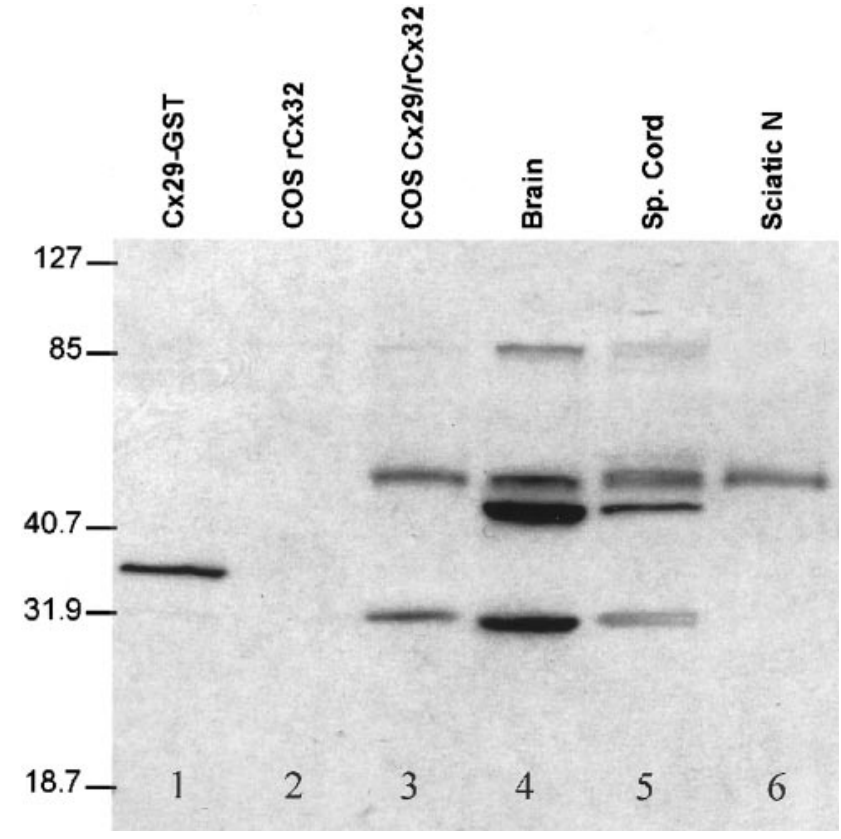

Figure 5. Cx29 displays anomalous behavior in Western blots. Affinitypurified anti-Cx29 antibody was produced against a GST fusion protein containing C-terminal residues 220-258. Lane 1, Ten nanograms of purified GST fusion protein. Lane 2, COS cells transfected with $\mathrm{rCx} 32$ provide negative control for anti-Cx29 antibody. Lane 3, COS cells cotransfected with $\mathrm{rCx} 32$ and $\mathrm{Cx} 29$. Bands at $\sim 29,60$, and $85 \mathrm{kDa}$ were detected. Lane 4, Total proteins from adult mouse brain. Strong labeling of several bands in addition to the ones detected in COS cells was observed, possibly resulting from proteolytic digestion (see Discussion). Lane 5, Total proteins from mouse spinal cord present a similar pattern to brain. Lane 6, Total proteins from mouse sciatic nerve. In sciatic nerve, the $60 \mathrm{kDa}$ band was more abundant relative to the $29 \mathrm{kDa}$ band.

odal axolemma (Arroyo and Scherer, 2000). Cell bodies containing Cx29 generally did not exhibit $\mathrm{Cx} 32$ at levels that could be detected by this procedure (Fig. 6A). All three anti-Cx29 antibodies produced the same pattern of staining, which could be eliminated by absorption with the cognate immunogen (data not shown). We observed comparable patterns of labeling in the olfactory bulb, the cerebrum at the level of the hippocampus, the cerebellum, and pons (data not shown).

The double labeling for $\mathrm{Cx} 29$ and Caspr in the CNS also revealed that large myelinated axons typically expressed much less Cx29 than small ones (Fig. 6B). Caspr is an intrinsic membrane protein that is highly concentrated in the paranodal axolemma and thus provides a convenient marker for locating nodes and assessing the fiber diameter. The image in Figure $6 B$ contains many small diameter fibers exhibiting internodal and juxtaparanodal Cx29, whereas the four largest pairs of paranodes (dark blue arrowheads) are not associated with detectable Cx29 staining. In addition, the modest overlap (indicated by yellow) between the Caspr (green) and Cx29 (red) indicated that Cx29 was less concentrated at paranodes than elsewhere along the myelin sheaths of these small myelinated axons.

situ hybridization for Cx29 mRNA (arrows, examples of NeuN-positive cells; arrowheads, Cx29-positive cells). C, Similarly, GFAP-positive cells do not express Cx29 mRNA (arrows, examples of GFAP-positive cells; arrowheads, Cx29-positive cells). 

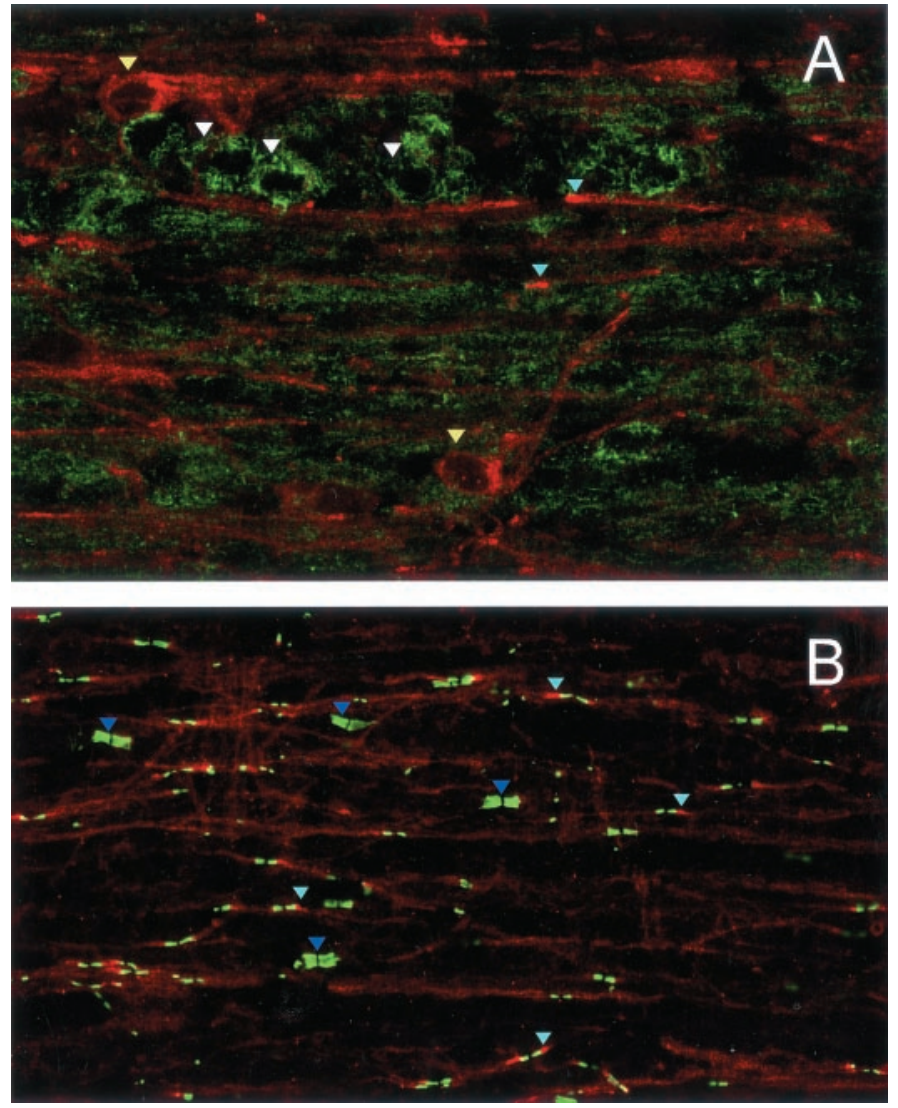

Figure 6. Cx29 and Cx32 are expressed in different subsets of spinal cord oligodendrocytes. Confocal images of horizontal sections of mouse spinal cord double labeled for Cx29 (A,B; red) and Cx32 (A; green) or Caspr $(B$; green) are shown. $\mathrm{Cx} 29$ labels the internodes and juxtaparanodes $(A, B$; light blue arrowheads) of small diameter fibers and a few somata $(A$; yellow arrowheads). The $\mathrm{Cx} 32$ antibody labels the somata of intrafascicular oligodendrocytes $(A$; white arrowheads), and labeling extends into fiber tracts. The Caspr antibody $(B)$ strongly labels the paranodal axolemma, thereby illuminating the point that large axons have little Cx29 immunostaining ( $B$; dark blue arrowheads).

\section{Cx29 and Cx32 are both expressed in Schwann cells but are differentially localized}

We performed similar studies of adult mouse and rat sciatic nerves, taking advantage of the ability to tease nerves into small groups of myelinated fibers. Figure 7 displays two myelinated fibers from a rat, double stained for Cx29 and Cx32. Because the anti-Cx32 antibodies did not work well after aldehyde fixation, this preparation was unfixed, and preservation of structure was not optimal. Nevertheless, $\mathrm{Cx} 32$ was enriched in the outer aspects of paranodes and incisures, as reported previously (Bergoffen et al., 1993; Scherer et al., 1995; Chandross et al., 1996). In contrast, Cx29 staining was evident in the inner aspects of paranodes and juxtaparanodes and appeared to be more uniformly distributed in incisures than Cx32 (also see Fig. 8 for Cx29 staining at incisures).

Figure 7 also shows $\mathrm{Cx} 29$ enrichment in a region corresponding to the inner mesaxon, the site where the first layer of the myelin sheath contacts itself. To explore this internodal Cx29 signal, we used double labeling for $\mathrm{Cx} 29$ and MAG (Fig. 8A) or Kv1.2 (Fig. $8 B$ ). Fortunately, these antibodies were compatible with aldehyde fixation; therefore, the quality of the preservation in these micrographs was high. MAG was found in the adaxonal Schwann cell
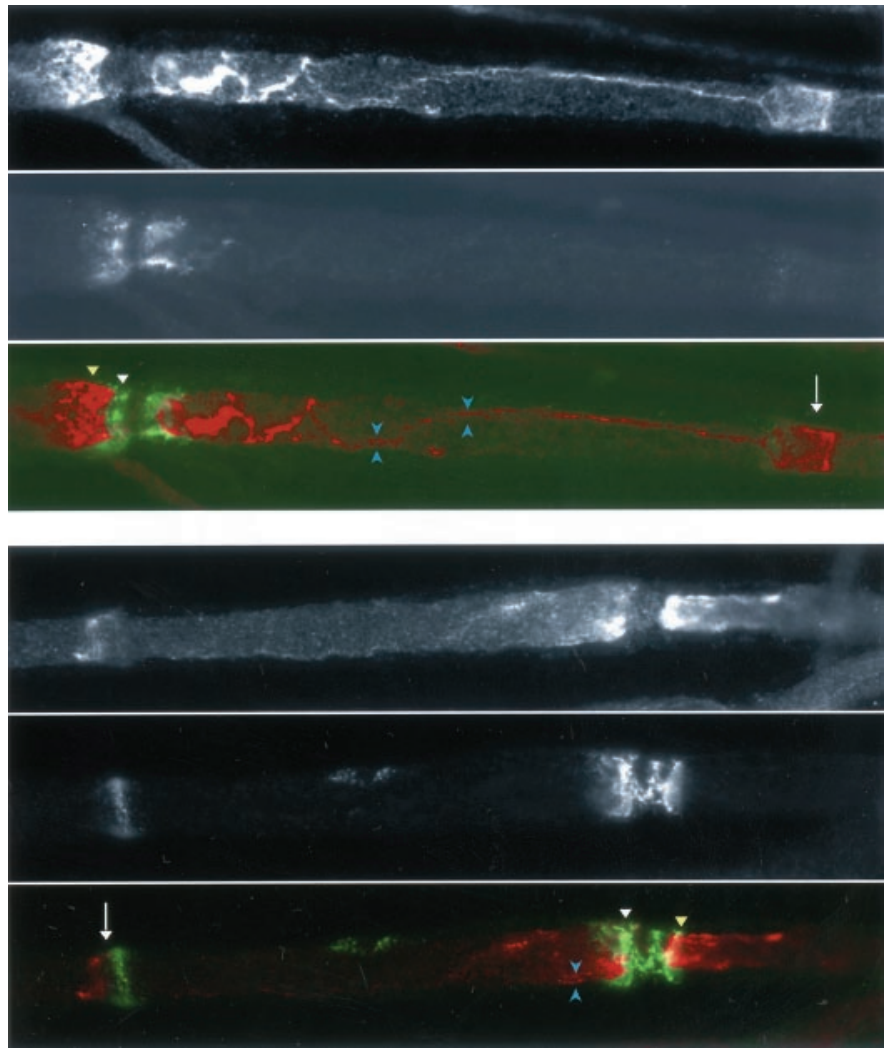

Figure 7. Cx29 and Cx32 are distinctly localized in myelinating Schwann cells. These are images of unfixed teased fibers from rat sciatic nerve, after double labeling for Cx29 (red) and Cx32 (green). Cx32 is strongly expressed in the outermost aspects of paranodes (white arrowheads) and incisures (white arrows). Cx29 is localized primarily to the innermost aspects of paranodes and juxtaparanodes (yellow arrowheads) and more uniformly in incisures (white arrows). Cx29 was enriched in the inner mesaxon (bracketed by blue arrowheads), which spans the internodal region.

membrane and was highly concentrated in the inner mesaxon, incisures, and paranodes (Sternberger et al., 1979; Trapp and Quarles, 1984). In Figure $8 A$, the internodal Cx29 signal consisted of a pair of lines that flanked the single line of MAG staining. Thus, Cx29 was enriched adjacent to the inner mesaxon. This conclusion was supported by colocalization studies of Cx29 and Kv1.2 (Fig. 8B). Kv1.2 is an axonal membrane protein highly enriched in the juxtaparanode and near the inner mesaxon. Internodal Cx29 and Kv1.2 signals strongly overlapped. They also overlapped at the juxtaparanode, but $\mathrm{Cx} 29$ extended farther into the paranode than Kv1.2. In the smallest myelinated fibers, there was uniform internodal Cx29 staining (data not shown), as was reported previously for Cx32 (Scherer et al., 1995).

Because Kv1.2 is a neuronal product, its striking colocalization with Cx29 left open the possibility that Cx29 was present in axolemma as well as Schwann cell plasma membrane. Therefore, pre-embedding electron microscopic immunocytochemistry was used to probe the subcellular distribution of Cx29. Antibody binding was detected using a peroxidase-amplification protocol. Labeling was readily observed in the innermost aspects of paranodes and juxtaparanodes and throughout the radial extent of incisures (Fig. 9). Inner mesaxon staining was difficult to obtain in a single plane of section and is not evident in this figure. Together, the immunocytochemistry was most consistent with the expression of Cx29 by Schwann cells, although the possibility of 

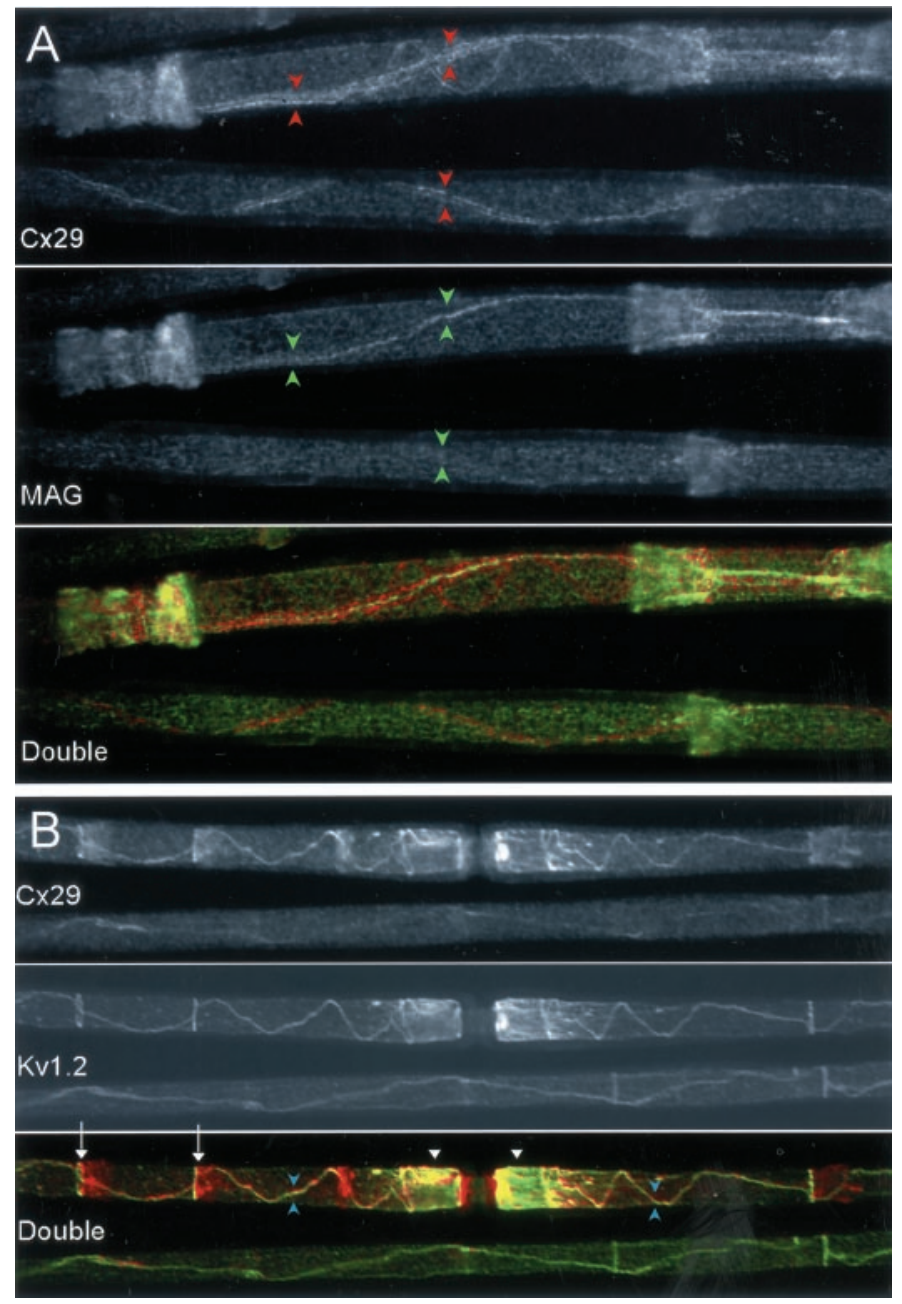

Figure 8. $\mathrm{Cx} 29$ is localized to the inner mesaxon. These are images of fixed teased fiber from rat sciatic nerve, after double labeling for $\mathrm{Cx} 29$ (red) and either MAG (A; green) or Kv1.2 (B; green). A, The internodal Cx29 signal consists of a pair of lines (bracketed by red arrowheads) that flank a single line of MAG staining (bracketed by green arrowheads); Cx29 and MAG colabel incisures. B, Cx29 and Kv1.2 are strikingly aligned both at the inner mesaxon (bracketed by blue arrowheads) and at the innermost aspect of incisures (arrows). The double nature of the Cx29 and Kv1.2 signals is not apparent at this magnification. Cx29 immunoreactivity is present in the paranode (red region nearest node of Ranvier) and juxtaparanode (yellow area marked by white arrowheads).

low levels and/or highly localized neuronal expression could not be excluded.

As myelination progresses and the nodes of Ranvier mature, many myelin-related proteins, including MAG, Caspr, and Kv1.2, undergo striking changes in their subcellular distribution (Baba et al., 1999). To assess possible changes in the distribution of Cx29, we performed double-label immunocytochemistry for Cx29 and MAG on sciatic nerve obtained from rats on P3 and P10 (Fig. 10). At P3, MAG is diffusely distributed throughout the internodal region (Fig. $10 \mathrm{~B}$ ), but by $\mathrm{P} 10$, it has largely redistributed into paranodes and incisures (Fig. 10D). In contrast, Cx29 is not diffusely localized at P3 but is already concentrated adjacent to developing nodes (Fig. 10A). By P10, MAG and Cx29 display very similar distributions at this level of resolution (Fig. 10B,D). The early concentration of $\mathrm{Cx} 29$ is consistent with our finding that Cx29 mRNA expression precedes that of PLP.
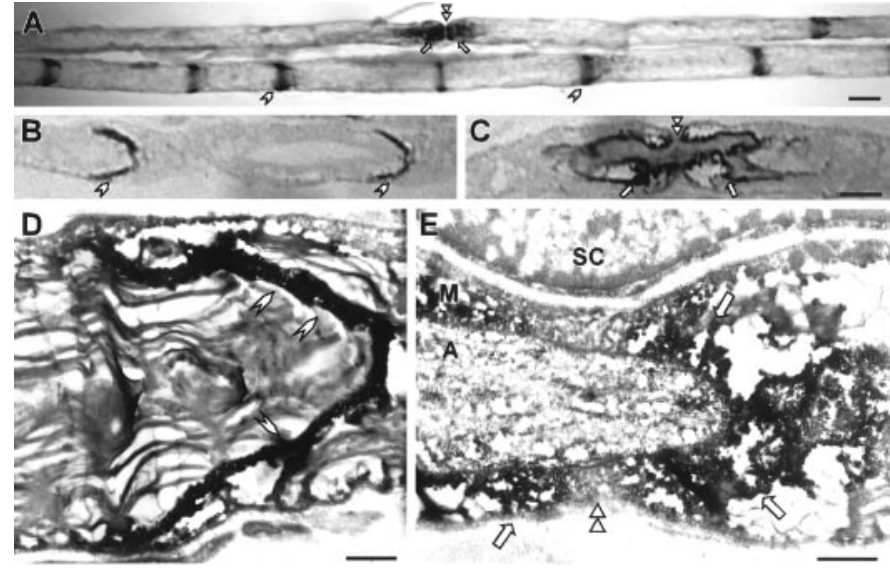

Figure 9. Immuno-EM of Cx29. These are images of teased fibers that were fixed in $0.5 \%$ glutaraldehyde, immunostained for Cx29 using DAB as the substrate for peroxidase, and processed for EM. Two teased fibers are illustrated in $A$, unstained semithin sections are shown in $B$ and $C$, and thin sections photographed with an electron microscope are shown in $D$ and $E$. In all panels, there is DAB throughout incisures (arrowheads) and in the innermost aspects of the juxtaparanodal/paranodal regions (arrows) of myelinating Schwann cells. SC, Schwann cell nucleus; $M$, myelin sheath; $A$, axon. Double arrowheads, Node of Ranvier. Scale bars: $A-C, 10 \mu \mathrm{m} ; D$, $E, 1 \mu \mathrm{m}$.
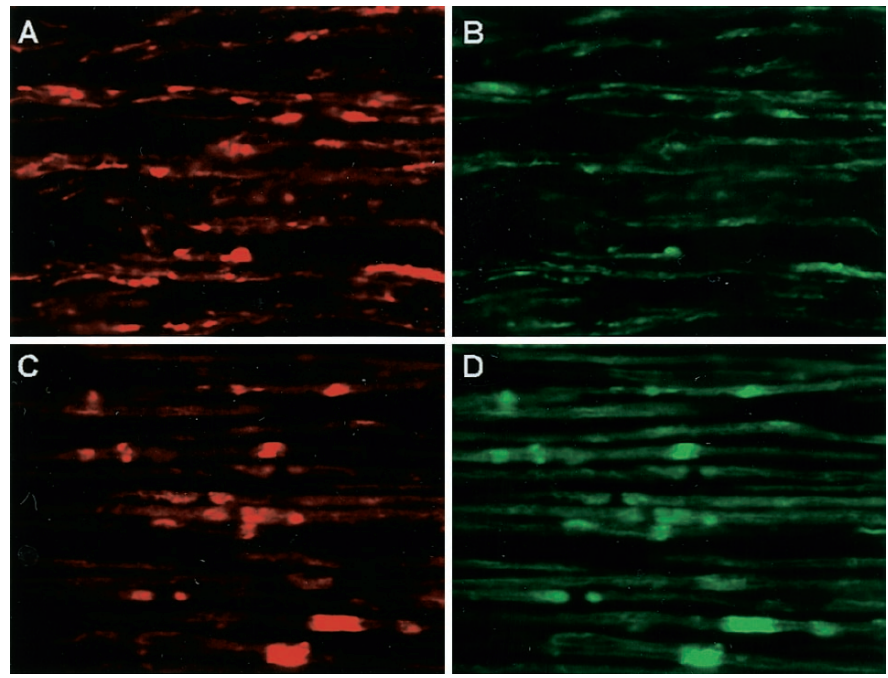

Figure 10. Developmental expression of $\mathrm{Cx} 29$. These are images of sections of rat sciatic nerve, double labeled for $\mathrm{Cx} 29$ (red; $A, C)$ and $\mathrm{MAG}$ (green; $B, D$ ). At P3, MAG $(B)$ is mostly diff usely distributed throughout the internodal region, whereas $\operatorname{Cx} 29(A)$ is less diffusely localized and more concentrated adjacent to developing nodes. By P10, both MAG and Cx29 display similar distributions $(C, D)$.

\section{Cx29 channel physiology}

To determine whether $\mathrm{Cx} 29$ could form intercellular channels, we used the paired Xenopus oocyte expression system (Swenson et al., 1989). However, paired oocytes expressing Cx29 did not reliably develop intercellular conductance (data not shown). In addition, we transfected N2A cells (Veenstra et al., 1992) with Cx29 and used dual whole-cell patch clamp to monitor conductance. Transfected cells were identified using eGFP fluorescence. Like oocyte pairs, no intercellular conductance was detected in N2A cells expressing Cx29 $(n=10)$. In contrast, positive controls of transfected $\mathrm{Cx} 32$ developed robust coupling (Fig. 11A). Im- 

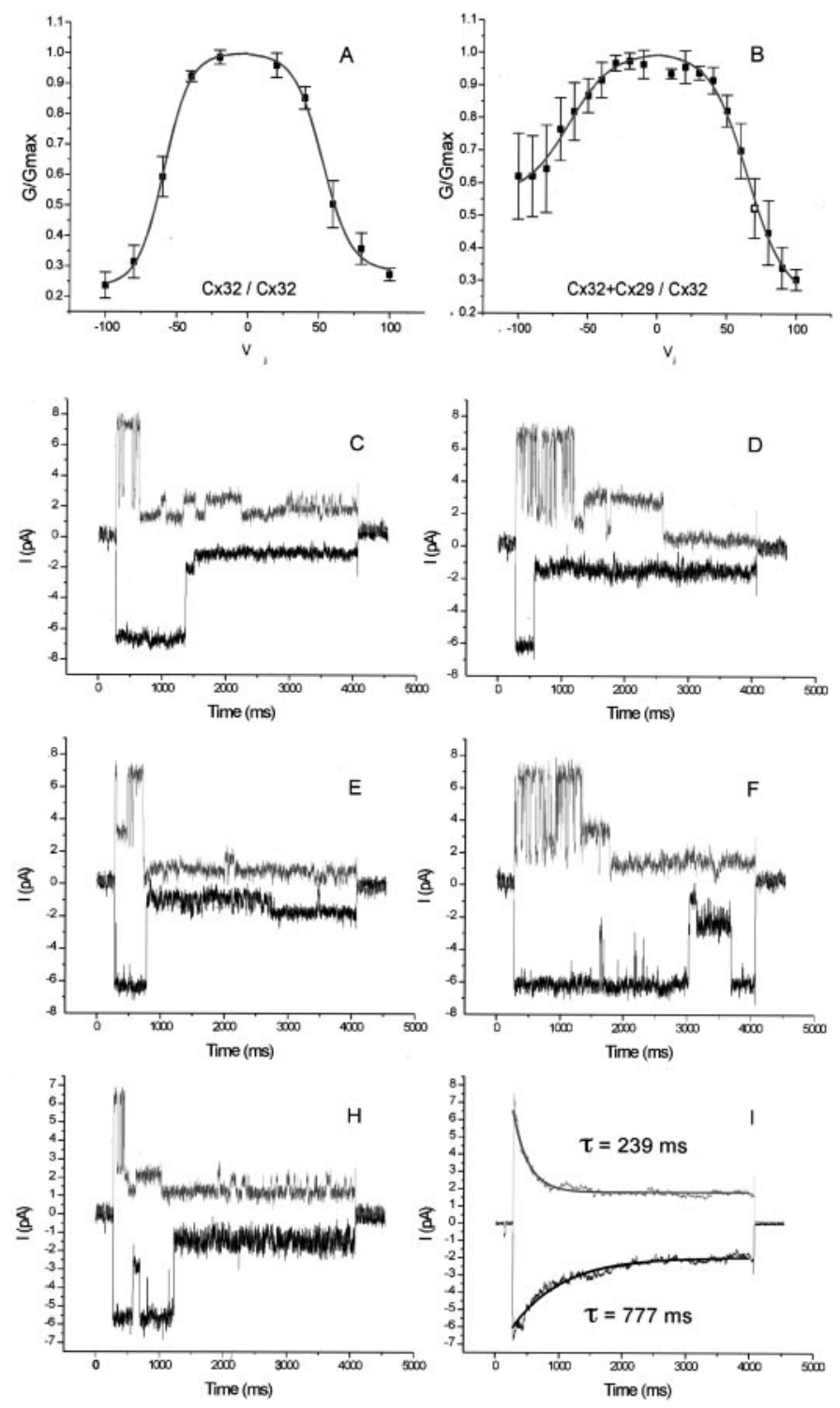

Figure 11. Cx29 forms heteromeric channels with Cx32. Connexins were expressed in $\mathrm{N} 2 \mathrm{~A}$ cells by transient transfection along with fluorescent markers, and dual whole-cell patch recording was performed. $A$, Normalized conductance-transjunctional voltage $\left(G_{j}-V\right)$ relationship in control pairs expressing only $\mathrm{Cx} 32$. Junctional conductance is symmetrical and displays $V_{\mathrm{j}}$-dependent inactivation $(n=7)$. The $G_{\mathrm{j}}-V_{\mathrm{j}}$ relationship fitted a double Boltzmann distribution whose fit is superimposed (solid line). B, $G_{\mathrm{j}}-V$ relationship in pairs expressing $\mathrm{C} \times 32$ in one cell and both $\mathrm{Cx} 32$ and Cx29 in the other $(n=7)$. The relationship is no longer symmetrical. The $V_{\mathrm{j}}$ indicated on the $x$-axis is applied to the cell containing both connexins. $C-H$, Representative examples of recordings from one cell pair with a single heteromeric channel. A transjunction potential of $100 \mathrm{mV}$ was imposed. The Cx32-only cell (top traces) exhibits an $\sim 70 \mathrm{pS}$ channel that rapidly transitions to several substates. The heteromeric channel exhibits similar single-channel conductances, but open states are prolonged without the frequent transitions to substates. The difference in gating behavior is exemplified in $I$, displaying the average of 30 of such sweeps. The average peak current for both polarities is $7-8 \mathrm{pA}$, but the time-dependent current decay was well fitted by a single exponential function (solid line) with a larger time constant for the heteromeric than for the homomeric side.

munocytochemistry and Western blotting were used to verify expression of $\mathrm{Cx} 29$ in transfected N2A cells (data not shown).

We then tested the ability of Cx29 to form heterotypic (different connexins in each cell) and heteromeric (more than one connexin in the same cell) channels with Cx32. eYFP and eGFP were used to unambiguously mark cells receiving particular combinations of connexins. No coupling was observed in heterotypic pairing of Cx29 and Cx32 (data not shown). However, heteromeric mixing of $\mathrm{Cx} 29$ and $\mathrm{C} x 32$ produced channels with properties different from those of $\mathrm{Cx} 32$ alone. Junctional currents in control pairs expressing only Cx32 (Fig. 11A) were symmetrical and displayed time-dependent inactivation in response to transjunctional potentials $\left(V_{\mathrm{j}}\right)$. Half-maximal inactivation of the conductance occurred at transjunctional voltages between 50 and 60 $\mathrm{mV}$. At $100 \mathrm{mV}$, the highest transjunctional potential tested, initial conductance dropped to $20 \%$ of maximal value. A plot of the normalized conductance versus $V_{\mathrm{j}}$ (Fig. $11 \mathrm{~A}$ ) closely matched a double Boltzmann distribution, in agreement with previous studies (Oh et al., 1999). However, in pairs expressing Cx32 in one cell and both $\mathrm{Cx} 32$ and $\mathrm{Cx} 29$ in the other, the conductancevoltage relationship was no longer symmetrical (Fig. 11B). At maximal transjunctional potential, initial conductance dropped to $60 \%$ on average in cells expressing both connexins. Thus, heteromeric hemichannels displayed less voltage sensitivity than homomeric hemichannels. We also noted the expected increase in the variability of the voltage response of heteromeric Cx29/Cx32 hemichannels compared with homomeric Cx32 hemichannels. This was anticipated because expression levels are rarely uniform from cell to cell in experiments involving transient transfection. Thus, the ratio of $\mathrm{Cx} 29$ to $\mathrm{Cx} 32$ was likely different in every pair tested.

Junctional currents recorded from one cell pair with a single active intercellular channel are shown in Figure $11 C-H$. The upper traces in each panel display junctional currents obtained in response to a $100 \mathrm{mV}$ transjunctional potential, where the $\mathrm{Cx} 32$ expressing cell was more positive. The bottom trace reflects imposition of a transjunctional potential of the opposite polarity. The Cx32-only cell (upper traces) exhibited activation of a $\sim 70$ $\mathrm{pS}$ channel that rapidly transitioned to substates, which is reasonably consistent with previous reports using N2A cells (Oh et al., 1999). The Cx29/Cx32 cell exhibited similar single-channel conductances but reproducibly displayed more prolonged open states without the frequent transitions to substates. The difference in gating behavior is exemplified in Figure 11I, which shows the average of 30 such sweeps. The average peak current for both polarities was 7-8 pA, but the time-dependent current decay followed a single exponential with a larger time constant for the heteromeric than for the homomeric side. From these results, we concluded that Cx29 can participate in the formation of heteromeric gap-junctional channels.

\section{DISCUSSION}

We identified Cx29, a novel connexin that was expressed predominantly if not exclusively in myelinating glial cells in both the CNS and PNS. As summarized in Figure 12, the expression of $\mathrm{Cx} 29$ and Cx32 in CNS myelin sheaths appeared to be mutually exclusive: Cx29 was localized to the inner aspects of small myelin sheaths, particularly in the juxtaparanodal region, whereas $\mathrm{Cx} 32$ was localized to the outer aspects of large myelin sheaths. Although all myelinating Schwann cells expressed both Cx29 and Cx32, their intracellular distributions differed. Cx29 was concentrated along the inner aspects of paranodes and especially juxtaparanodes, as well as in the inner mesaxon, whereas Cx32 was primarily found in the outer aspects of paranodes. Incisures contained both Cx29 and Cx32. Finally, although Cx29 alone did 


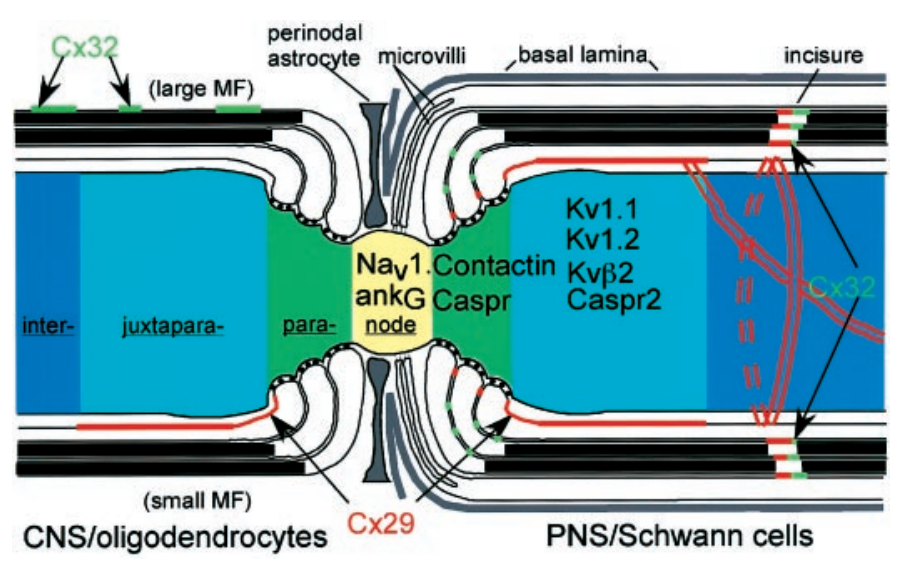

Figure 12. The organization of connexins in CNS and PNS myelin sheaths. This is a schematic depiction of a myelinated fiber that has both a CNS and PNS myelin sheath. The myelin sheath and axon are depicted as hemisected, and the internodal, paranodal, juxtaparanodal, and nodal regions are shown. In the PNS, Cx29 is depicted as localized to the adaxonal Schwann cell membrane (in the juxtaparanodal region, at the inner mesaxon, and at the innermost aspect of incisures) and between the glial loops in the paranodal region. In the CNS, Cx29 is depicted as localized to the adaxonal oligodendrocyte. $\mathrm{Cx} 32$ is localized to the incisures and paranodes of myelinating Schwann cells and the outer membrane of large myelinated fibers in the CNS [modified from Arroyo and Scherer (2000) and used with permission of Springer-Verlag].

not form active channels in Xenopus oocytes or N2A cells, it altered the properties of $\mathrm{Cx} 32$ channels.

\section{The roles of gap junctions in Schwann cells}

Myelinating Schwann cells are not joined by gap junctions (Tetzlaff, 1982). Rather, they contain reflexive gap junctions, initially identified by freeze-fracture EM, between the layers of the myelin sheath at incisures and paranodes (Sandri et al., 1977). Because we localized $\mathrm{Cx} 32$ in these same regions, we proposed that $\mathrm{Cx} 32$ forms the reflexive junctions, which allow ions and small molecules to diff use directly across the myelin sheath (Bergoffen et al., 1993). However, dye transfer between the Schwann cell body and periaxonal cytoplasm was not interrupted in cx32-null mice (Balice-Gordon et al., 1998), suggesting the existence of another connexin in the reflexive junctions. Cx26 and Cx43 have been reported in myelinating Schwann cells (Yoshimura et al., 1996; Z hao et al., 1999), but they are not generally observed (Scherer et al., 1995; Nagaoka et al., 1999). Nonmyelinating and denervated Schwann cells express a different set of connexins, but these could not contribute to reflexive junctions (Chandross et al., 1996; Mambetisaeva et al., 1999). Thus, Cx29 is likely to be the missing connexin. The overlap in the distribution of Cx29 and Cx32 at incisures and paranodes suggests that they both contribute to reflexive junctions, supplying similar and possibly redundant activity. However, the distribution of Cx29 is significantly broader than that of $\mathrm{Cx} 32$, most notably in juxtaparanodes. Thus, Cx29 might actually be more critical than $\mathrm{Cx} 32$ in establishing reflexive coupling. On this basis, we think it likely that a Cx29 knock-out mouse will develop a demyelinating neuropathy. By the same reasoning, mutations in the human ortholog (hCx31.3) might cause inherited demyelinating neuropathies.

Aspects of Cx29 distribution not shared by Cx32 suggest their involvement in functions other than reflexive coupling. In PNSmyelinated axons, the distributions of Cx29 and Kv1.2 near the inner mesaxon were indistinguishable, which was striking and unexpected for two reasons: there is no anatomical evidence for the establishment of gap junctions between axons and their myelin sheaths and, thus, no obvious explanation for the presence of a connexin at the inner mesaxon, and Cx29 and Kv1.2 are expressed in different cells and thus would not be expected to colocalize. Kv1.2, complexed with Kv1.1, Kv $\beta 2$, and Caspr2 (Poliak et al., 1999), is abundant in the juxtaparanodal region of myelinated axons but is also aligned with the inner mesaxon and the innermost aspect of incisures. The function of these $\mathrm{K}^{+}$ channels in peripheral nerve is not well understood. Because they are electrically isolated from the node (Chiu, 1991), they are not well located to facilitate repolarization, although they may dampen excitability (Browne et al., 1994; Shillito et al., 1995; Smart et al., 1998). Their localization suggests that they participate in the movement of $\mathrm{K}^{+}$between axoplasm and periaxonal space, and their association with $\mathrm{Cx} 29$ implicates this connexin in $\mathrm{K}^{+}$transport. We speculate that $\mathrm{Cx} 29$ hemichannels, gap junction channels active in a single plasma membrane (Paul et al., 1991; Verselis et al., 2000), could comprise a pathway for the removal of $\mathrm{K}^{+}$accumulating in periaxonal space during neural activity (Konishi, 1990; Chiu, 1991). In support of this notion, freezefracture studies reveal rosettes of particles in juxtaparanode, inner mesaxon, and incisures (Stolinski et al., 1985), which could correspond to $\mathrm{Cx} 29$ hemichannels. Thus, Kv1.1/1.2 channels in the axonal membrane, Cx29 hemichannels in the Schwann cell membrane, and Cx29 and Cx32 intercellular channels in the myelin sheath could function together to provide a mechanism for shuttling $\mathrm{K}^{+}$through noncompact myelin.

\section{Gap junctions in oligodendrocytes}

Like Schwann cells, oligodendrocytes express Cx29 and Cx32 (Dermietzel et al., 1989; Scherer et al., 1995; Li et al., 1997). However, these connexins seem to be expressed in mutually exclusive subsets of cells, at least in the spinal cord. Thus, although Cx29 and Cx32 may provide similar functions in different cells, they cannot provide functional redundancy in the manner proposed for Schwann cells. Potentially, other connexins provide redundancy in oligodendrocytes. A number of studies report expression of Cx45 in oligodendrocytes (Dermietzel et al., 1997; Kunzelmann et al., 1997; Pastor et al., 1998). However, mice expressing histological reporters in place of $\mathrm{Cx} 45$ display no oligodendrocyte expression (M. Deans and D. L. Paul, unpublished observations), so the significance of $\mathrm{Cx} 45$ antibody staining is not clear. On the other hand, we recently determined that $\mathrm{Cx} 47$, characterized previously as neuron specific (Teubner et al., 2001), is not present in neurons but is expressed in most, if not all, spinal cord oligodendrocytes (D. Menichella, Paul, K. A. Kleopa, and S. S. Scherer, unpublished observations). Thus, Cx47 may provide a redundant function for both Cx29 and Cx32 in oligodendrocytes.

Freeze-fracture EM demonstrates that most if not all gap junctions made by oligodendrocytes are with astrocytes (Massa and Mugnaini, 1982; Waxman and Black, 1984; Nagy et al., 1997; Rash et al., 2001). Junctional contacts with astrocytes are located at oligodendrocyte cell bodies, their proximal processes, and along the outer leaflet of the myelin sheath. It is likely that Cx32 (Dermietzel et al., 1989; Scherer et al., 1995; Kunzelmann et al., 1997) and possibly Cx47 comprise these gap junctions. However, physiological studies of junctional communication involving oligodendrocytes indicate tremendous heterogeneity. Oligodendrocytes may display no coupling, coupling to other oligodendrocytes but not astrocytes, coupling to astrocytes but not other oligodendrocytes, or coupling to both, essentially every possible pattern of 
communication (Butt and Ransom, 1989; Robinson et al., 1993; Venance et al., 1995; Pastor et al., 1998). These variations could, in part, reflect the differential expression of multiple connexins. As we have shown, the connexin content of adjacent spinal cord oligodendrocytes can be dramatically different. Additional complexity results from the expression of multiple connexins by astrocytes (Dermietzel et al., 1989; Kunzelmann et al., 1999; Nagy et al., 2001), which also show regional variation in connexin expression (Nagy et al., 1999). Thus, the anatomical relationships of oligodendrocytes and astrocytes and their connexin content may provide a molecular basis for the physiological findings.

In addition to conventional intercellular junctions, oligodendrocytes may also establish reflexive gap junctions between the wraps of myelin in the paranodes (Sandri et al., 1977). The connexin(s) that form these junctions has not been clearly identified. Although we do not observe Cx32-positive paranodes (Scherer et al., 1995), there is at least one report of them (Li et al., 1997). Our data suggest that Cx29 could form gap junctions in the juxtaparanodal region of smaller myelin sheaths in the CNS. Alternatively, juxtaparanodal $\mathrm{Cx} 29$ could form hemichannels in the CNS, as postulated above for the PNS. However, oligodendrocyte membranes do not contain particle rosettes resembling those observed in Schwann cells. It remains to be determined whether oligodendrocyte paranodes contain connexins or have reflexive gap junctions.

One striking difference in Cx29 distribution between the CNS and PNS was the lack of staining at the inner mesaxon in oligodendrocytes. Immunostaining at the ventral root entry zone (data not shown) suggests that this difference is not an artifact of tissue processing. Within the entry zone, the transition between PNS to CNS myelin occurs at a single node. Inner mesaxon staining for Cx29 is evident in the Schwann cell on one side of the transition node but not in the oligodendrocyte on the other side. A similar phenomenon happens for Kv1.1/Kv1.2: the internodal strands are not found in myelinated CNS axons (Arroyo et al., 2001). Thus, the molecular organization of myelinated axons in the PNS and CNS differs, albeit subtly.

Our data add to the long-standing recognition that oligodendrocytes may differ according to the numbers and sizes of the myelin sheaths they form. This idea began with the light microscopic observations of Del Rio-Hortega (1928), was confirmed by electron microscopy (Bunge, 1968), and has been extended recently to molecular phenotype (Butt and Berry, 2000). For example, oligodendrocytes associated with the smallest fibers express carbonic anhydrase isoform II (CAII) but not small isoforms of MAG (S-MAG), whereas those ensheathing the largest axons show the opposite pattern of expression (Butt and Berry, 2000). Our finding of mutually exclusive expression of Cx29 and Cx32 in CNS myelin sheaths confirms and extends the previous observation that a subset of CNS myelin sheaths expresses Cx32 (Li et al., 1997). The basis for this heterogeneity appears to be related to the caliber of the myelinated axon: large myelin sheaths surround large axons and contain $\mathrm{Cx} 32$; small myelin sheaths surround small axons and contain Cx29. Thus, Cx29, like CAII and S-MAG, may serve as a marker for functional differentiation among mature oligodendrocytes.

\section{Channel activity of Cx29}

The failure of $\mathrm{Cx} 29$ to reliably induce intercellular communication when expressed in heterologous systems is difficult to reconcile with some of the in vivo functions we have proposed. However, it cannot be concluded from our studies that $\mathrm{Cx} 29$ is incapable of forming active homotypic intercellular channels. Cx29 may appear inactive because neither oocytes nor N2A cells express a necessary cofactor or correctly balance several necessary factors. Regardless, activity in heteromeric intercellular configurations was demonstrated by the alterations in the voltage gating of $\mathrm{Cx} 32$ when coexpressed with $\mathrm{Cx} 29$. On this basis, it is reasonable to suggest that one in vivo function of $\mathrm{Cx} 29$ is to modulate the properties of other connexins or other types of channel proteins. This type of interaction between connexins has proven to be critical for normal development and homeostasis of the ocular lens (White, 2002). In Schwann cells, Cx32 could be a partner for $\mathrm{Cx} 29$ at incisures and paranodes, whereas in oligodendrocytes, $\mathrm{Cx} 47$ might play a similar role. These issues will be explored using knock-outs of Cx29, Cx32, and Cx47.

\section{REFERENCES}

Altevogt BM, Paul DL, Goodenough DA (2000) Cloning and characterization of a novel central nervous system specific connexin, mouse connexin29. Mol Biol Cell [Suppl] 11:330a.

Anzini P, Neuberg DHH, Schachner M, Nelles E, Willecke K, Zielasek J, Toyka KV, Suter U, Martini R (1997) Structural abnormalities and deficient maintenance of peripheral nerve myelin in mice lacking the gap junction protein connexin 32. J Neurosci 17:4545-4551.

Arroyo EJ, Scherer SS (2000) On the molecular architecture of myelinated fibers. Histochem Cell Biol 113:1-18.

Arroyo EJ, Xu T, Poliak S, Watson M, Peles E, Scherer SS (2001) Internodal specializations of myelinated axons in the central nervous system. Cell Tissue Res 305:53-66.

Baba H, Akita H, Ishibashi T, Inoue Y, Nakahira K, Ikenaka K (1999) Completion of myelin compaction, but not the attachment of oligodendroglial processes triggers $\mathrm{K}(+)$ channel clustering. J Neurosci Res 58:752-764.

Balice-Gordon RJ, Bone LJ, Scherer SS (1998) Functional gap functions in the schwann cell myelin sheath. J Cell Biol 142:1095-1104.

Bergoffen J, Scherer SS, Wang S, Scott MO, Bone LJ, Paul DL, Chen K, Lensch MW, Chance PF, Fischbeck KH (1993) Connexin mutations in X-linked Charcot-Marie-Tooth disease. Science 262:2039-2042.

Browne DL, Gancher ST, Nutt JG, Brunt ER, Smith EA, Kramer P, Lit M (1994) Episodic ataxia/myokymia syndrome is associated with point mutations in the human potassium channel gene, KCNA1. Nat Genet 8:136-140.

Bunge RP (1968) Glial cells and the central myelin sheath. Physiol Rev 48:197-251.

Butt AM, Berry M (2000) Oligodendrocytes and the control of myelination in vivo: new insights from the rat anterior medullary velum. J Neurosci Res 59:477-488.

Butt AM, Ransom BR (1989) Visualization of oligodendrocytes and astrocytes in the intact rat optic nerve by intracellular injection of lucifer yellow and horseradish peroxidase. Glia 2:470-475.

Chandross KJ, Kessler JA, Cohen RI, Simburger E, Spray DC, Bieri P, Dermietzel R (1996) Altered connexin expression after peripheral nerve injury. Mol Cell Neurosci 7:501-518.

Chiu SY (1991) Functions and distribution of voltage-gated sodium and potassium channels in mammalian Schwann cells. Glia 4:541-558.

Del Rio-Hortega P (1928) Tercera aportación al conocimiento morfológico e interpretción funcional de la oligodendroglia. Mem Real Soc Esp Hist Nat 14:5-122.

Dermietzel R, Traub O, Hwang TK, Beyer E, Bennett MVL, Spray DC, Willecke K (1989) Differential expression of three gap junction proteins in developing and mature brain tissue. Proc Natl Acad Sci USA 86:10148-10152.

Dermietzel R, Farooq M, Kessler JA, Althaus H, Hertzberg EL, Spray DC (1997) Oligodendrocytes express gap junction proteins connexin32 and connexin45. Glia 20:101-114.

Duncan ID, Hammang JP, Trapp BD (1987) Abnormal compact myelin in the myelin-deficient rat: absence of proteolipid protein correlates with a defect in the intraperiod line. Proc Natl Acad Sci USA 84:6287-6291.

Einheber S, Zanazzi G, Ching W, Scherer S, Milner TA, Peles E, Salzer JL (1997) The axonal membrane protein Caspr, a homologue of neurexin IV, is a component of the septate-like paranodal junctions that assemble during myelination. J Cell Biol 139:1495-1506.

Gabriels JE, Paul DL (1998) Connexin43 is highly localized to sites of disturbed flow in rat aortic endothelium but connexin 37 and connexin40 are more uniformly distributed. Circ Res 83:636-643.

Haefliger J-A, Bruzzone R, Jenkins NA, Gilbert DJ, Copeland NG, Paul DL (1992) Four novel members of the connexin family of gap junction proteins. Molecular cloning, expression, and chromosome mapping.
J Biol Chem 267:2057-2064. 
Hertzberg E (1984) A detergent-independent procedure for the isolation of gap junctions from rat liver. J Biol Chem 259:9936-9943.

Jiang JX, White TW, Goodenough DA, Paul DL (1994) Molecular cloning and functional characterization of chick lens fiber connexin45.6. Mol Biol Cell 5:363-373.

Kleopa KA, Yum SW, Scherer SS (2002) Cellular mechanisms of connexin32 mutations associated with CNS manifestations. J Neurosci Res 68:522-534.

Konishi T (1990) Voltage-gated potassium currents in myelinating Schwann cells in the mouse. J Physiol (Lond) 431:123-139.

Kunzelmann P, Blumcke I, Traub O, Dermietzel R, Willecke K (1997) Coexpression of connexin 45 and -32 in oligodendrocytes of rat brain. J Neurocytol 26:17-22.

Kunzelmann P, Schroder W, Traub O, Steinhauser C, Dermietzel R, Willecke K (1999) Late onset and increasing expression of the gap junction protein connexin30 in adult murine brain and long-term cultured astrocytes. Glia 25:111-119.

Lemke G, Axel R (1985) Isolation and sequence of a cDNA encoding the major structural protein of peripheral myelin. Cell 40:501-508.

Li J, Hertzberg EL, Nagy JI (1997) Connexin32 in oligodendrocytes and association with myelinated fibers in mouse and rat brain. J Comp Neurol 379:571-591.

Mambetisaeva ET, Gire V, Evans WH (1999) Multiple connexin expression in peripheral nerve, Schwann cells, and Schwannoma cells. J Neurosci Res 57:166-175.

Massa PT, Mugnaini E (1982) Cell junctions and intramembrane particles of astrocytes and oligodendrocytes: a freeze-fracture study. Neuroscience 7:523-538.

Mi H, Deerinck TJ, Ellisman MH, Schwarz TL (1995) Differential distribution of closely related potassium channels in rat Schwann cells. J Neurosci 15:3761-3774.

Milner RJ, Lai C, Nave KA, Lenoir D, Ogata J, Sutcliffe JG (1985) Nucleotide sequences of two mRNAs for rat brain myelin proteolipid protein. Cell 42:931-939.

Mirsky R, Jessen KR (1990) Schwann cell development and the regulation of myelin. Semin Neurosci 2:423-435.

Mullen RJ, Buck CR, Smith AM (1992) NeuN, a neuronal specific nuclear protein in vertebrates. Development 116:201-211.

Nagaoka T, Oyamada M, Okajima S, Takamatsu T (1999) Differential expression of gap junction proteins connexin26, 32, and 43 in normal and crush-injured rat sciatic nerves. Close relationship between connexin43 and occludin in the perineurium. J Histochem Cytochem 47:937-948.

Nagy JI, Ochalski PAY, Li J, Hertzberg EL (1997) Evidence for the co-localization of another connexin with connexin-43 at astrocytic gap junctions in rat brain. Neuroscience 78:533-548.

Nagy JI, Patel D, Ochalski PA, Stelmack GL (1999) Connexin30 in rodent, cat and human brain: selective expression in gray matter astrocytes, co-localization with connexin43 at gap junctions and late developmental appearance. Neuroscience 88:447-468.

Nagy JI, Li X, Rempel J, Stelmack G, Patel D, Staines WA, Yasumura T, Rash JE (2001) Connexin26 in adult rodent central nervous system: demonstration at astrocytic gap junctions and colocalization with connexin30 and connexin43. J Comp Neurol 441:302-323.

Neuberg DH, Sancho S, Suter U (1999) Altered molecular architecture of peripheral nerves in mice lacking the peripheral myelin protein 22 or connexin32. J Neurosci Res 58:612-623.

Oh S, Rubin JB, Bennett MV, Verselis VK, Bargiello TA (1999) Molecular determinants of electrical rectification of single channel conductance in gap junctions formed by connexins 26 and 32 . J Gen Physiol 114:339-364.

Pastor A, Kremer M, Moller T, Kettenmann H, Dermietzel R (1998) Dye coupling between spinal cord oligodendrocytes: differences in coupling efficiency between gray and white matter. Glia 24:108-120.

Paul DL (1986) Molecular cloning of cDNA for rat liver gap junction protein. J Cell Biol 103:123-134.

Paul DL, Ebihara L, Takemoto LJ, Swenson KI, Goodenough DA (1991) Connexin46, a novel lens gap junction protein, induces voltage-gated currents in nonjunctional plasma membrane of Xenopus oocytes. J Cell Biol 115:1077-1089.

Poliak S, Gollan L, Martinez R, Custer A, Einheber S, Salzer JL, Trimmer JS, Shrager P, Peles E (1999) Caspr2, a new member of the neurexin superfamily, is localized at the juxtaparanodes of myelinated axons and associates with K+ channels. Neuron 24:1037-1047.

Radeke MJ, Misko TP, Hsu C, Herzenberg LA, Shooter EM (1987) Gene transfer and molecular cloning of the rat nerve growth factor receptor. Nature 325:593-597.

Rash JE, Yasumura T, Dudek FE, Nagy JI (2001) Cell-specific expression of connexins and evidence of restricted gap junctional coupling between glial cells and between neurons. J Neurosci 21:1983-2000.

Robinson SR, Hampson ECGM, Munro MN, Vaney DI (1993) Unidirectional coupling of gap junctions between neuroglia. Science 262:1072-1074.
Rodriguez CI, Dymecki SM (2000) Origin of the precerebellar system. Neuron 27:475-486.

Sandri C, Van Buren JM, Akert K (1977) Membrane morphology of the vertebrate nervous system. A study with freeze-etch technique. Prog Brain Res 46:1-384

Scherer SS, Salzer JL (2001) Axon-Schwann cell interactions in peripheral nerve regeneration. In: Glial cell development (Jessen KR, Richardson WD, eds), pp 299-330. Oxford: Oxford UP.

Scherer SS, Braun PE, Grinspan J, Collarini E, Wang DY, Kamholz J (1994) Differential regulation of the $2^{\prime}$, $3^{\prime}$-cyclic nucleotide $3^{\prime}$ phosphodiesterase gene during oligodendrocyte development. Neuron 12:1363-1375

Scherer SS, Deschenes SM, Xu YT, Grinspan JB, Fischbeck KH, Paul DL (1995) Connexin32 is a myelin-related protein in the PNS and CNS. J Neurosci 15:8281-8294.

Scherer SS, Xu YT, Nelles E, Fischbeck K, Willecke K, Bone LJ (1998) Connexin32-null mice develop demyelinating peripheral neuropathy. Glia 24:8-20.

Shillito P, Molenaar PC, Vincent A, Leys K, Zheng W, van den Berg RJ, Plomp JJ, van Kempen GT, Chauplannaz G, Wintzen AR (1995) Acquired neuromyotonia: evidence for autoantibodies directed against $\mathrm{K}+$ channels of peripheral nerves. Ann Neurol 38:714-722.

Smart SL, Lopantsev V, Zhang CL, Robbins CA, Wang H, Chiu SY, Schwartzkroin PA, Messing A, Tempel BL (1998) Deletion of the $\mathrm{K}(\mathrm{V}) 1.1$ potassium channel causes epilepsy in mice. Neuron 20:809-819.

Sohl G, Eiberger J, Jung YT, Kozak CA, Willecke K (2001) The mouse gap junction gene connexin29 is highly expressed in sciatic nerve and regulated during brain development. J Biol Chem 382:973-978.

Srinivas M, Rozental R, Kojima T, Dermietzel R, Mehler M, Condorelli DF, Kessler JA, Spray DC (1999) Functional properties of channels formed by the neuronal gap junction protein connexin36. J Neurosci 19:9848-9855.

Sternberger NH, Quarles RH, Itoyama Y, Webster HD (1979) Myelinassociated glycoprotein demonstrated immunocytochemically in myelin and myelin-forming cells of developing rat. Proc Natl Acad Sci USA 76:1510-1514.

Stolinski C, Breathnach AS, Thomas PK, Gabriel G, King RH (1985) Distribution of particle aggretates in the internodal axolemma and adaxonal Schwann cell membrane in rodent peripheral nerve. J Neurol Sci 67:213-222.

Swenson KI, Jordan JR, Beyer EC, Paul DL (1989) Formation of gap junctions by expression of connexins in Xenopus oocyte pairs. Cell $57: 145-155$.

Tetzlaff W (1982) Tight junction contact events and temporary gap junctions in the sciatic nerve fibres of the chicken during Wallerian degeneration and subsequent regeneration. J Neurocytol 11:839-858.

Teubner B, Odermatt B, Guldenagel M, Sohl G, Degen J, Bukauskas F, Kronengold J, Verselis VK, Jung YT, Kozak CA, Schilling K, Willecke K (2001) Functional expression of the new gap junction gene connexin47 transcribed in mouse brain and spinal cord neurons. J Neurosci 21:1117-1126.

Trapp BD, Quarles RH (1984) Immunocytochemical localization of the myelin-associated glycoprotein. Fact or artifact? J Neuroimmunol 6:231-249.

Veenstra RD, Wang HZ, Westphale EM, Beyer EC (1992) Multiple connexins confer distinct regulatory and conductance properties of gap junctions in developing heart. Circ Res 71:1277-1283.

Venance L, Cordier J, Monge M, Zalc B, Glowinski J, Giaume C (1995) Homotypic and heterotypic coupling mediated by gap junctions during glial cell differentiation in vitro. Eur J Neurosci 7:451-461.

Verselis VK, Trexler EB, Bukauskas FF (2000) Connexin hemichannels and cell-cell channels: comparison of properties. Braz J Med Biol Res 33:379-389.

Waxman SG, Black JA (1984) Freeze-fracture ultrastructure of the perinodal astrocyte and associated glial junctions. Brain Res 308:77-87.

White TW (2002) Unique and redundant connexin contributions to lens development. Science 295:319-320.

White TW, Paul DL (1999) Genetic diseases and gene knockouts reveal diverse connexin functions. Annu Rev Physiol 61:283-310.

Willecke K, Temme A, Teubner B, Ott T (1999) Characterization of targeted connexin32-deficient mice: a model for the human CharcotMarie-Tooth (X-type) inherited disease. Ann NY Acad Sci 883:302-309.

Yoshimura T, Satake M, Kobayashi T (1996) Connexin43 is another gap junction protein in the peripheral nervous system. J Neurochem 67:1252-1258.

Zamboni L, de Martino C (1967) Buffered picric-acid formaldehyde: a new rapid fixative for electron-microscopy. J Cell Biol 35:148A.

Zhao S, Fort A, Spray DC (1999) Characteristics of gap junction channels in Schwann cells from wild-type and connexin-null mice. Ann NY Acad Sci 883:533-537. 